Accepted for publication in Journal of Experimental Psychology: Learning, Memory, and Cognition @2019 APA, https://www.apa.org/pubs/journals/xlm/. This article may not exactly replicate the final published version. It is not the copy of record.

\title{
Structural priming is determined by global syntax rather than internal phrasal structure: Evidence from young and older adults
}

\author{
Sophie M. Hardy ${ }^{a^{*}}$ \\ Linda Wheeldon ${ }^{\mathrm{b}}$ \\ Katrien Segaert ${ }^{\mathrm{a}, \mathrm{c}}$
}

\footnotetext{
${ }^{\text {a }}$ School of Psychology, University of Birmingham, UK

${ }^{\mathrm{b}}$ Department of Foreign Languages and Translations, University of Agder, Norway

${ }^{\mathrm{c}}$ Centre for Human Brain Health, University of Birmingham, UK
}

*Corresponding author: School of Psychology, University of Birmingham, Edgbaston, Birmingham, B15 2TT, UK. Email: smh649@bham.ac.uk.

\section{Author Note}

The full set of stimuli is provided online on the Open Science Framework (https://osf.io/8y5jx/). This research was partly supported by an Economic and Social Research Council (ESRC) studentship awarded to Sophie M. Hardy from the University of Birmingham Doctoral Training Centre (grant number: ES/J50001X/1). The authors gratefully acknowledge the help of Denise Clissett, the coordinator of the Patient and Lifespan Cognition Database. We also thank Katherine Messenger for providing us with the picture stimuli, Jan Zandhuis for technical support, and Robyn Bell, Nathaniel Crawley, Clara Hewitt, Lauren Holder and Laura Hoole for assistance with data collection. 


\begin{abstract}
Structural priming refers to the tendency of speakers to repeat syntactic structures across sentences. We investigated the extent to which structural priming persists with age and whether the effect depends upon highly abstract syntactic representations that only encompass the global sentence structure or whether representations are specified for internal constituent phrasal properties. In Experiment 1, young and older adults described transitive verb targets that contained the plural morphology of the patient role ("The horse is chasing the frogs/ The frogs are being chased by the horse"). While maintaining the conceptual and global syntactic structure of the prime, we manipulated the internal phrasal structure of the patient role to either match (plural; "The king is punching the builders/ The builders are being punched by the king") or mismatch (coordinate noun phrase; "The king is punching the pirate and the builder/ The pirate and the builder are being punched by the king") the target. In both age groups, we observed limited priming of onset latencies, but robust effects of choice structural priming - participants produced more passive targets following passive primes - which critically did not vary dependent on whether the internal constituent structure matched or mismatched between the prime and target. Experiment 2 replicated these findings for the agent role: choice structural priming was unaffected by age or changes to the prime noun phrase type. This demonstrates that global, not internal, syntactic structure determines syntactic choices in young and older adults, as predicted by residual activation and implicit learning models of structural priming.
\end{abstract}

Keywords: structural priming; ageing; sentence production; syntactic representations; syntactic planning. 


\section{Introduction}

To communicate successfully, a speaker must convert a conceptual representation of the information that they wish to convey into an appropriate syntactic structure (Bock \& Levelt, 1994; Garrett, 1980; Levelt, 1989). For some messages, more than one syntactic structure can be used to convey the same core meaning; for example, a transitive verb event can either be expressed using an active sentence ("the girl is chasing the boy") or a passive sentence ("the boy is being chased by the girl"). In these instances, the syntactic structure that a speaker chooses reflects the relationship between thematic representations of the message to be expressed and the syntactic properties to which they are assigned (i.e., whether the agent or patient of the transitive verb action is assigned to the subject or object position). One factor that has been pervasively found to influence syntactic choices is structural priming: the facilitation of syntactic processing that occurs when a syntactic structure is repeated across an otherwise unrelated prime and target pair (Bock, 1986; Pickering \& Ferreira, 2008). For example, a speaker will be more likely to use the passive syntax to describe a transitive verb target if they have recently processed a passive prime sentence as opposed to the alternative active sentence (see Mahowald, James, Futrell, \& Gibson, 2016, or a meta-analtyical review). Importantly, structural priming can provide a window into how speakers represent syntax independent of lexical content, allowing insight into the abstractness of syntactic representations (Branigan, 2007).

In this study, we used the structural priming paradigm to investigate which factors influence syntactic choices in order to gain insight into the abstractness of syntactic representation and the processes involved throughout the lifespan in syntax generation and planning. Our aims were two-fold. Firstly, we aimed to investigate whether structural priming is determined solely by the repetition of the highly abstract, or global, syntactic structure that lacks phrase structure detail or whether changes to the internal phrasal structure influence the magnitude of structural priming. Changes in the structural priming effect that are dependent on whether global or local structure is repeated across the prime and target can test predictions about the abstraction of syntactic representations made by existing models of structural priming (e.g., Chang, Dell, \& Bock, 2006; Pickering \& Branigan, 1998). Both structural choice and on-line sentence planning processes are essential for producing a fluent and coherent sentence (Levelt, 1989). We therefore examined whether repetition of global 
and local structure affected a speaker's choice to use an active or a passive sentence to describe a transitive verb target, as well as how long they took to begin articulation (a measure of on-line sentence planning). Secondly, we aimed to investigate the effect of ageing on syntactic choices and sentence planning by testing both young and older adults. This is because the processes determining syntactic choices and sentence planning may vary across the lifespan due to the extensive cognitive and neuroanatomical changes that occur with healthy ageing, such as a decline in processing speed and a reduction in grey matter volume (Good et al., 2001; Salthouse, 1996), which may in turn lead to older adults adopting different strategies when processing language (see Peelle, 2019, for a review).

In the following introduction, we first review the current theoretical models of structural priming along with the evidence for the role of constituent phrasal structure in sentence production. We then outline the design and predictions of the current study.

\section{Influence of Constituent Structure on Structural Priming}

Models of structural priming have tended to postulate that priming reflects facilitated linguistic processing that occurs when either a speaker is accessing a syntactic structure (Malhotra, Pickering, Branigan, \& Bednar, 2008; Pickering \& Branigan, 1998), formulating it (Chang et al., 2006; Chang, Dell, Bock, \& Griffin, 2000; Jaeger \& Snider, 2013) or a combination of the two (Reitter, Keller, \& Moore, 2011; Segaert, Wheeldon, \& Hagoort, 2016). What these models have in common is that they largely assume that the complete syntactic structure is represented in a highly abstract form (i.e., only encompasses the global syntax and is unspecified for detailed constituent information). For example, Pickering and Branigan (1998) propose that syntactic structures are represented by combinatorial nodes within the lexicon which encompass the broader phrasal structure (e.g., that a passive sentence contains a prepositional by-phrase), but are unspecified for more detailed constituent information, such as the internal structure of the constituent phrases. According to the model, processing of a prime structure activates the relevant combinational node to an abovebaseline level, and this residual activation drives the repeated selection of the primed syntax when a speaker must then describe a syntactically-related target. Importantly, Pickering and Branigan (1998) argue that syntactic representations must be shallow and monostratal in nature (i.e., unspecified for internal phrasal features) in order for abstract representations to 
be generalisable across multiple utterances (see Branigan \& Pickering, 2017, for a more extensive explanation).

A second account of structural priming relates to error-based implicit learning (Chang, 2002; Chang et al., 2000, 2006). According to this more computational model, language users create expectations based on linguistic input, which they use to anticipate upcoming words in a sentence. If a different word is heard to what is expected, this can result in prediction error (e.g., when processing a prime relating to the comparatively less frequent passive syntax). This then leads to a slight change in the mappings between message-level representations and abstract syntactic structures (driven by implicit learning), which biases the speaker toward expressing the syntactically-similar target message using the primed syntax. Critically though, Chang and colleagues argue that implicit learning must occur at an abstract level of syntax that is independent of the internal properties of a sentence, such as the sequence of words within constituent phrases. This is because the model's dual-path architecture would become distinctly less effective if syntactic constituents were represented differently depending on their internal features (e.g., separate units for "I", "the boy" and "the old apple" instead of a singular noun phrase unit), leading to interference during sentence processing and production.

Consequently, both the residual activation (Pickering \& Branigan, 1998) and implicit learning (Chang et al., 2006) models predict that structural priming is determined solely by the repetition of the global syntactic structure. If this is the case, the magnitude of structural priming should be unaffected by changes to the constituent phrasal features of the sentence, relating to both the closed-class content (i.e., function words and affixes) and open-class content (i.e., nouns, lexical verbs and adjectives). However, as we now discuss, the evidence for the role of constituent structure on structural priming is not as clear-cut as the models may suggest.

\section{Evidence for the role of constituent structure on structural priming.}

To first consider the effect of closed-class content, Bock (1989) found that dative verb primes with a 'to' or a 'for' in the prepositional phrase (e.g., "A cheerleader offered a seat to her friend / saved a seat for her friend") equally primed production of a target sentence with the preposition 'to' (e.g., "The girl handed the paintbrush to the man", instead of the 
double-object alternative "The girl handed the man the paintbrush"). Likewise, dative verb priming is unaffected by whether the prime and target contain the same or different closedclass morphemes in the verb phrase (e.g., "the teacher [gave/gives/was giving] the homework to the children"), suggesting that the combinatorial nodes representing syntax are unspecified for verb tense (Pickering \& Branigan, 1998). Such evidence may be considered to support the assumption of structural priming models that repetition of global syntactic structure is what drives the priming effect. However, Ziegler, Snedeker, and Wittenburg (2017) question the complete abstractness of syntactic representations, and instead argue that combinatorial nodes must encompass some functional lexical content at a more internal level since it is possible to prime the use of function words. For example, speakers can be primed to mention or not mention the function word 'that' in an embedded clause sentence (e.g., "The mechanic mentioned [that] the car could use a tune-up"); this is despite the fact that the presence or absence of 'that' does not affect the overall meaning or syntactic structure (Ferreira, 2003). Similar priming effects have been found for the use of the optional verb-doubling structure in Chinese (Francis, Matthews, Wong, \& Kwan, 2011), and the use of the second determiner in coordinate noun phrases (e.g., "the cat and [the] dog"; Temperley, 2005).

To now turn to the role of open-class content, the evidence of their role in structural priming is also mixed. On the one hand, Pickering and Branigan (1998) found that the inclusion of adjectives did not affect dative verb priming (e.g., "The racing driver showed the manager the torn overall" primed "The patient showed the doctor his spots"), as would be expected if syntactic structures are represented in a highly abstract form. Likewise, the magnitude of structural priming has been found to be unaffected by the addition of a subordinate clause to one of the existing phrases (e.g., "The professor offered the students his theories [that had insulted many people] "; Fox Tree \& Meijer, 1999) or when the dative structure appears as a complement within an embedded clause sentence (e.g., "John said that [the girl gave the boy the puppy]; Branigan, Pickering, McLean, \& Stewart, 2006). However, Melinger and Dobel (2005) observed structural priming from single verb primes that are restricted to a particular syntactic structure (e.g., in English 'contribute' can only occur within a prepositional dative structure); this suggests that structural representation can be accessed via verbs, indicating that priming effects are not always driven solely by repetition of global syntactic structure. 
Moreover, structural priming is enhanced when open-class words are repeated between the prime and target (lexical boost; see Mahowald et al., 2016, for a review). Pickering and Branigan (1998) account for this effect by proposing that there is an additional lemma node representing the head lexical item (the verb in a dative or transitive sentence) that is activated in conjunction with the relevant combinatorial node. However, this explanation cannot account for why lexical boost has been found for the repetition of nonhead lexical items, such as nouns in dative sentences (Scheepers, Raffray, \& Myachykov, 2017) or adjectives in relative noun phrases (Cleland \& Pickering, 2003). Such findings challenges Pickering and Branigan's (1998) argument that syntactic representations are highly abstract in nature and unspecified for open-class content as they explicitly propose that nonhead lexical items are represented within an internal phrasal structure, and thus their repetition should not affect the magnitude of structural priming. By contrast, lexical boost (of both head and non-head lexical items) does not present a challenge for Chang et al.'s (2006) model as they instead propose that lexical boost is driven by explicit memory traces of the prime that are entirely dissociated from abstract syntactic representations (see also Chang, Janciauskas, \& Fitz, 2012).

To summarise, although the theoretical models of structural priming postulate that syntactic representations are highly abstract and unspecified for internal phrasal structure, studies investigating the role of closed/open-class content on structural priming have provided conflicting evidence. We aimed to directly address this question by investigating the effect of differences in the complexity of the noun phrase structure between prime and target transitive verb sentences on the magnitude of structural priming. Unlike previous studies, we strove to maintain that all features relating to conceptual and global syntactic structure were equal between the prime and target sentences. Any differences in the magnitude of priming we observed, therefore, relate directly to differences in the complexity of the internal phrasal structure.

\section{Influence of constituent noun phrase structure on structural priming.}

Nouns represent open-class content in a sentence, and while previous studies have focused on the inclusion or omission of adjectives and subordinate phrases (Fox Tree \& Meijer, 1999; Pickering \& Branigan, 1998), no study to date to our knowledge has 
manipulated the open-class content within the complexity of the noun phrase while maintaining the conceptual and semantic elements of the sentence (e.g., the number of thematic roles). The semantic content of a sentence is largely borne through the noun phrases (Keizer, 2007); hence, structural priming effects may be more sensitive to changes in the noun phrase than in other open-class content. We note that previous studies have demonstrated that it is possible to prime repetition of the noun phrase (Bernolet, Hartsuiker, \& Pickering, 2007; Branigan, McLean, \& Jones, 2005; Cleland \& Pickering, 2003; Melinger \& Cleland, 2011). However, these studies have predominantly used simple and relative noun phrases (e.g., "the red square" vs. "the square that is red") in which the noun is the head lexical item and the noun phrase also encompasses the complete (i.e., global) syntactic representation of the sentence. Thus, in simple and relative noun phrases, the noun phrase structure is likely to be represented on a more independent level and does not form a constituent part of a larger syntactic structure. By contrast, the noun phrases of a transitive verb sentence each represent one part of the larger syntactic structure, relating to the subject noun phrase at the beginning of the sentence and the object noun phrase at the end of sentence (see Figure 1). As such, constituent noun phrases are highly likely to be represented differently, and consequently affected differently by structural priming, compared to the more global noun phrase structures.
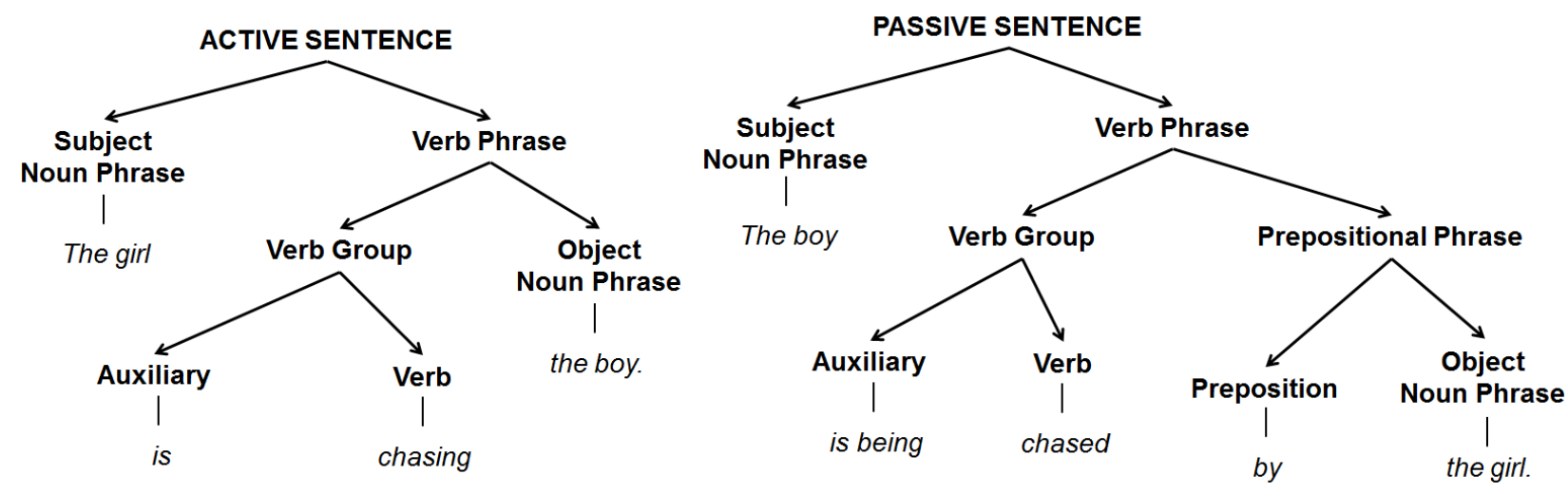

Figure 1. Syntax trees of the structure of an active and a passive transitive verb sentence. In an active sentence, the subject noun phrase refers to the agent of action and the object noun phrase refers to the patient of the action. In a passive sentence, this is reversed and there is an additional prepositional 'by' phrase. 
In this study we specifically investigated the extent to which structural priming persists when the prime contained a coordinate noun phrase structure, but the target contained a plural noun phrase structure. We investigated this at four points in a transitive sentence - at the subject and object noun phrase of both an active and a passive sentence. For example, is a passive target sentence with a plural noun phrase in the patient role (as in 1) primed equally by a prime containing the same phrasal structure as the target (as in $2 \mathrm{a}$ ) compared to a prime containing a different subject coordinate noun phrase structure (as in $2 \mathrm{~b}$ )?

(1) Target: "The frogs are being chased by the horse"

(2a) Same phrase prime: "The builders are being punched by the king"

(2b) Different phrase prime: "The pirate and the builder are being punched by the king"

The extent to which structural priming persists when the noun phrase structure differs between the prime and target will be informative about the effect of constituent phrasal structure on primed syntactic choices and the degree of abstractness of the syntactic representations involved. Specifically, our study tests current models of structural priming that propose that syntactic structures are represented in a highly abstract manner. According to the residual activation model (Pickering \& Branigan, 1998), we expect to find equal structural priming effects of the passive syntax when the primed syntactic structure both matches (2a) and mismatches ( $2 b)$ that of the target because combinatorial nodes within the lexicon only represent global syntactic structure and are unspecified for constituent phrasal structure. Likewise, according to the implicit learning model (Chang et al., 2006), we expect equal structural priming regardless of differences in prime noun phrase structure because, within the dual-path model, constituent structures are represented within a single unit irrespective of differences in the internal sequence of words.

\section{Investigating Structural Priming Effects of Onset Latencies}

In addition to syntactic choices, we measured structural priming effects on speech onset latencies. How quickly a speaker begins articulation is informative about the underlying mechanisms at the planning stage of sentence generation (Levelt, 1989; Wheeldon, 2013). Indeed, repetition of syntactic structure has been found to decrease speech onset latencies, indicating a facilitated processing effect, particularly when the preferred alternative, such as the active, is primed (Corley \& Scheepers, 2002; Segaert, Menenti, Weber, \& Hagoort, 2011; 
Segaert, Weber, Cladder-Micus, \& Hagoort, 2014; Segaert et al., 2016; Smith \& Wheeldon, 2001; Wheeldon \& Smith, 2003). This positive preference effect on primed onset latencies is in contrast to the inverse preference effect observed for syntactic choices (i.e., greater choice priming of the dispreferred structure; Ferreira \& Bock, 2006). This highlights how structural priming may have different effects at the selection and planning stage of sentence production. Moreover, while the selection of a global syntactic structure may occur prior to articulation, the actual planning of the sentence occurs incrementally in smaller more manageable units (Kempen \& Hoenkamp, 1987; Levelt, 1989, 1992). An incremental system is beneficial as it allows for the rapid release of parts of the sentence as soon as planning is complete, reducing the demands on working memory. Indeed, evidence suggests that speakers typically plan the first phrase prior to speech onset with planning for the rest of the sentence occurring during articulation (see Wheeldon, 2013, for a review). For example, speakers have been found to take longer to initiate sentences containing larger initial phrases, supporting a phrasal scope of advanced planning (Hardy, Segaert, \& Wheeldon, 2018; Levelt \& Maassen, 1981; Martin, Crowther, Knight, Tamborello, \& Yang, 2010; Martin, Yan, \& Schnur, 2014; Smith \& Wheeldon, 1999), although the degree and type of pre-planning may vary according to the linguistic structure of a given language (Hwang \& Kaiser, 2014, 2015; Myachykov, Scheepers, Garrod, Thompson, \& Fedorova, 2013). Taken together, this highlights why it is important to examine choice and onset latency priming effects in conjunction, in order to gain a more complete understanding of the processes involved in fluent sentence production.

Segaert et al.'s (2016) two-stage competition model is the first to account for structural priming effects at both the selection and planning of sentence production (see also Segaert et al., 2011, 2014). According to the model, alternative syntactic structures (e.g., active vs. passive) are represented by competing nodes, with activation levels determined by the relative frequency of the structure. Sentence production begins with construction of the preverbal message and this is followed by two sequential stages. First is the selection stage during which a speaker selects one syntactic structure from competing alternatives, followed by the planning stage during which the selected syntax is incrementally planned and produced. Choice priming effects are determined solely at the selection stage and are a reflection of the activation levels of competing syntactic structures, the levels of which are influenced by the preceding prime (increased activation of the node representing the primed 
syntactic structure). By contrast, onset latency priming effects are determined by the time taken to complete both the selection and planning stage. While repetition of syntactic structure always reduces time taken at the planning stage, time taken at the selection stage is only reduced for the active prime. This is because processing of the preferred syntactic structure increases the difference in activation levels between the two alternatives, thus reducing selection time. In this way, greater latency priming effects are observed for the preferring syntactic structure. Within our structural priming study, we therefore expect to observe greater latency priming effects when participants choose to use an active sentence to describe the target compared to when they choose to use a passive sentence (similar to Segaert et al., 2011, 2016).

A more interesting and novel prediction though concerns the effect of noun phrase complexity on the magnitude of latency priming. The planning stage of Segaert et al.'s (2016) two-stage competition model is based on Levelt's (1989) principles of incremental planning, meaning that planning of the first unit, likely relating to the initial phrase, is prioritised prior to articulation. Thus, repetition of constituent noun phrase structures may have a different effect on onset latencies dependent on whether the repetition occurs in the initial subject noun phrase or final object noun phrase (see Figure 1). Specifically, within our study, we may expect to observe facilitatory priming of latencies when the subject phrase is repeated (relating to the agent role of an active sentence, but the patient role of a passive sentence) because this initial part of the sentence in typically planned prior to articulation and therefore any benefits to planning are observable in decreased onset latencies. However, we expect to find no or minimal speed priming benefits when the final object phrase is repeated (relating to the patient role of an active sentence, but the agent role of a passive sentence) because planning for this part of the sentence occurs later during articulation, meaning that any latency benefits are unlikely. Moreover, we may also find differences in the magnitude of the structural priming effect between young and older adults if there are age-related changes in the selection and planning of syntactic structures, as we now discuss.

\section{Influence of Ageing on Structural Priming}

There is not a straightforward relation between healthy ageing and decline in language abilities; instead the relationship is more complex as some language skills are more 
negatively affected by ageing than others (for reviews, Burke \& Shafto, 2008; Peelle, 2019). Age-related declines in language production are apparent at both the word and sentence level. Older adults are slower and more error-prone in picture naming tasks (see Feyereisen, 1997, for a meta-analytical review). Similarly, with age, there is a decline in the production of complex syntactic structures, such as embedded clauses, coupled with an increase in syntactic errors, such as the use of the incorrect tense (Kemper, 1987; Kemper, Greiner, Marquis, Prenovost, \& Mitzner, 2001; Kemper \& Sumner, 2001; Rabaglia \& Salthouse, 2011). However, other language skills are characterised by stability with age, such as the ability to switch between the production of different syntactic alternatives (Altmann \& Kemper, 2006; Davidson, Zacks, \& Ferreira, 2003). Ageing is also associated with certain language improvements, such as increased vocabulary size and knowledge (Verhaeghen, 2003). Agerelated declines in language production are likely related to other emerging cognitive deficits, such as a decline in processing speed and working memory (Abrams \& Farrell, 2011; Kemper \& Sumner, 2001; Salthouse, 1996), and reduced integrity in the brain regions that support language functions, such as the left interior frontal gyrus and the left anterior insula (Peelle, Troiani, Wingfield, \& Grossman, 2010; Shafto, Burke, Stamatakis, Tam, \& Tyler, 2007). However, older adults are often able to adopt effective processing strategies, such as the recruitment of additional brain regions, in order to compensate for lost efficiency elsewhere, thereby explaining why not all language skills are negatively affected by ageing (see Wingfield \& Grossman, 2006, for review).

This contrast between decline and preservation creates a multi-faceted picture of language processing during healthy ageing, which, according to Peelle's (2019) 'supply and demand' framework, can be characterised by the complex interplay between the demands of a given language task and an individual's neurocognitive capacity for the task (see Baltes \& Baltes, 1990, for a similar model of gains vs. losses management in psychological well-being in ageing). Within this study, we sought to examine how the processes involved in syntax selection and planning are affected by ageing by compared groups of healthy young and older adults. Specifically, we aimed to understand whether: (a) young and older adults represent syntactic representations in a similar or different manner for both global and local features of a sentence; (b) both age groups rely on the same processes when selecting a syntactic alternative in a primed situation; and (c) age-related differences exist in the incremental 
planning of chosen syntactic structures. Answering these questions is important for fully understanding the complex balance between decline and preservation in healthy ageing.

To date, only a few studies have investigated the effect of old age on choice structural priming; however, this has produced mixed results with two studies finding evidence of preserved priming of passives in older adults (Hardy, Messenger, \& Maylor, 2017; Heyselaar, Wheeldon, \& Segaert, 2018), while others have not (Heyselaar, Segaert, Walvoort, Kessels, \& Hagoort, 2017, footnote 2; Sung, 2015). ${ }^{1}$ Moreover, all of these studies have only focused on the effect of global syntactic structure (active vs. passive) on the production of passive targets, and have not considered the role of internal phrasal structure on the magnitude of structural priming. Manipulating the local, as well as the global, structure of the prime can provide greater insight into age-related changes in syntactic representations, thus helping to clarify the debate within the existing literature. Moreover, including a measure of onset latency priming can help provide a more complete picture of the age-related changes that occur at both the selection and planning stage of sentence production.

Both the residual activation (Pickering \& Branigan, 1998) and two-stage competition (Segaert et al., 2016) models include a spreading activation architecture, whereby the node representing the prime syntactic structure is activated to an above-baseline level (which then drives reselection during target processing). However, according to Salthouse's (1996) general slowing model of ageing, declines in processing speed with age can substantially decrease the speed of spreading activation within a cognitive or neural network, a factor which may be related to age-related atrophy of the frontal and cerebellar regions (see Eckert, 2011, for a review). Applied to structural priming, this would predict that, when older adults process a prime sentence, the node representing the structure might not activate quickly enough to a level that could influence syntactic choices on the subsequent target trial or to a level which would benefit the speed of planning of the chosen syntactic structure. In addition, Segaert et al.'s (2016) model includes an element of inhibition as each node representing the syntactic alternatives will inhibit the other node in relation to its own activation level (e.g.,

\footnotetext{
${ }^{1}$ Note, other studies have tested non-young adults as controls for clinical patients; however, the samples are often small and the age range large. While three such studies did find evidence of structural priming in controls (Cho-Reyes, Mack, \& Thompson, 2016; Ferreira, Bock, Wilson, \& Cohen, 2008; Yan, Martin, \& Slevc, 2018), a fourth did not (Hartsuiker \& Kolk, 1998).
} 
hearing a passive prime will increase the activation of the passive node while also inhibiting the activation of the active node). However, according to the transmission deficit model, ageing is accompanied by declines in the strength of positive and negative (i.e., inhibitory) connections among units within a given network (MacKay \& Abrams, 1998; MacKay \& Burke, 1990). Such an age-related decline in the strength of the connections between syntactic nodes may also result in levels of activation of the syntactic representations that are insufficient for structural priming effects to occur. We may therefore expect to observe less structural priming effects in older speakers compared to young speakers due to age-related differences in processing speed and emerging transmission deficits.

By contrast, the implicit learning model (Chang et al., 2006) would predict similar structural priming effects, at least at the choice level, in young and older adults because implicit learning skills are largely unaffected by healthy ageing (Fleischman, Wilson, Gabrieli, Bienias, \& Bennett, 2004; Light \& Singh, 1987). As such, both age groups should experience a similar change in mappings between message-level representations and abstract syntactic structures when processing an unexpected passive prime sentence. Notably, all three structural priming models largely predict that any age-related differences or invariance in priming should be equal whether or not the internal phrasal structure matches or mismatches between the prime and target as they assume that abstract syntactic representations only encompass the global sentence structure. However, age group differences in structural priming, particularly relating to onset latencies, may emerge due to differences in the internal phrase structure of the prime if age-related changes exist in the flexibility of sentence planning processes.

The ability to plan sentences incrementally in a chunk-like manner is essential for fluent sentence production (Levelt, 1989). To our knowledge, only one study to date has specifically examined on-line sentence planning processes in older adults. Hardy et al. (2018) found that, although both young and older adults took longer to initiate sentences with a larger initial phrase, there were age group differences in the flexibility of planning scope. Unlike young adults, older adults did not benefit from a preview of lexical information beyond the initial phrase and this premature access to the lexical information (i.e., outside of their preferred phrasal planning scope) actually made them more error-prone. One explanation for this age-related effect on lexical processing may be that older adults' 
planning scope is more rigidly fixed to phrasal boundaries. Hardy et al. (2018)'s study therefore provides the first evidence that healthy ageing affects some aspects of on-line sentence planning; however, many questions are still to be addressed. Within our study, we aimed to specifically investigate older adults' sentence planning in a task in which syntactic choice was also involved and in which repetition of the global and internal structure was manipulated between the prime and the target. As such, our study will provide added insight into age-related effects on on-line sentence planning. It could be that older adults' increased sensitivity to phrasal boundaries (as found by Hardy et al., 2018) means that they are also more sensitive to the constituent features within phrases. This may in turn mean that, compared to young adults, the magnitude of the latency priming effects displayed by older adults may be more strongly influenced by whether or not the internal noun phrase structure is repeated between the prime and target.

\section{The Present Study}

In this study, we investigated the effect of global syntactic and internal phrasal structure on the magnitude of choice and onset latency structural priming. Specifically, we aimed to test the predictions of current models of structural priming that syntactic choices are driven by repetition of global, not internal, syntactic structure (Chang et al., 2006; Pickering \& Branigan, 1998), and that faciliatory priming effects on sentence planning should be greater when the structure of the initial phrase is repeated (Segaert et al., 2016). Young and older adults completed a structural priming task in which we either manipulated the noun phrase structure of the patient role (Experiment 1) or the agent role (Experiment 2). We conducted the two experiments as we considered that the patient role may be more syntactically important in the production of a passive sentence because it appears in the initial subject phrase, while the agent role may be more conceptually salient because it ranked higher on the thematic hierarchy (Christianson \& Ferreira, 2005). Participants described transitive verb targets using either an active or a passive sentence that contained the plural morphology of the patient role (Experiment 1; "the horse is chasing the frogs" / "the frogs are being chased by the horse") or the agent role (Experiment 2: "the horses are chasing the frog" / "the frog is being chased by the horses"). We manipulated whether the preceding active or passive prime contained the same constituent noun phrasal structure as the target or 
a different coordinate noun phrase structure in the patient or agent role. Crucially, the manipulation of the prime phrasal structure did not affect the global syntactic structure of the sentence or the main conceptual features (always one agent acting on two patients in Experiment 1 and two agents acting on one patient in Experiment 2).

We measured structural priming effects at the choice level of sentence production (the proportion of target passives produced in each prime condition), as well as at the planning level (target onset latencies). The extent to which choice structural priming effects persist when the constituent noun phrase structure differs between the prime and target will be informative about the complete abstractness of syntactic representations. The magnitude of onset latency priming effects when the initial subject phrase structure is repeated between the prime and target, compared to when the final object phrase is repeated, will provide insight into the phrasal scope of planning and how sensitive this is to changes in the constituent phrasal structure. Finally, the extent to which choice and latency structural priming effects differ between young and older adults will be informative about age-related changes in syntax selection and the flexibility of planning scope. 


\section{Method}

\section{Experiment 1: Manipulating the Patient Role}

Participants. We recruited 40 young adults aged 18-22 from the University of Birmingham student population (compensated with course credits) and 40 older adults aged 62-85 from the departmental Patient and Lifespan Cognition Database (compensated monetarily). All participants were native English speakers with normal or corrected-tonormal vision, and did not report any language disorders. See Table 1 for an overview of the sample characteristics. The study was approved by the University of Birmingham Ethical Review Committee and informed written consent was obtained prior to the test session.

Table 1. Background characteristics of the young and older adult participant groups for Experiments 1 and 2.

\begin{tabular}{lcccc}
\hline \multirow{2}{*}{ Characteristic } & \multicolumn{2}{c}{ Experiment 1 } & \multicolumn{2}{c}{ Experiment 2 } \\
\cline { 2 - 5 } & Young & Older & Young & Older \\
\hline$N($ Male/Female) & $40(4 / 36)$ & $40(20 / 20)$ & $40(10 / 30)$ & $40(16 / 24)$ \\
Age (years) & $19.7(0.7)$ & $73.9(6.0)$ & $19.7(0.9)$ & $72.6(5.4)$ \\
Education $^{\mathrm{a}}$ & $6.0(0.0)$ & $5.6(1.6)$ & $6.0(0.0)$ & $5.7(1.3)$ \\
General cognitive ability $^{\mathrm{b}}$ & -- & $27.5(0.9)$ & -- & $28.0(1.4)$ \\
\hline
\end{tabular}

Note. All values are given as means (with standard deviation) except for $N$ (Male/Female). ${ }^{\text {EEducation }}$ was scored on a scale of 0 (pre-primary school) to 8 (university doctorate) according to the International Standard Classification of Education (United Nations, 2011). ${ }^{\mathrm{b}}$ General cognitive ability was measured using the Montreal Cognitive Assessment (Nasreddine et al., 2005): all older adults scored 26 or above (out of 30) indicating that they were currently experiencing healthy ageing (scores $<26$ indicate risk of mild cognitive impairment or dementia; Smith, Gildeh, \& Holmes, 2007).

Design. Our design featured five different prime conditions (Figure 2). Each trial consisted of a coloured prime followed by a greyscale transitive verb target. The target could be described using an active or a passive sentence that contained the plural morphology of the patient role (as in 2). In the baseline prime condition (1a), an intransitive verb prime was followed by the transitive verb target (2): this enabled us to directly measure the production of actives and passives that were not primed by a prior transitive verb sentence. In all other prime conditions, a transitive verb prime (1b) was followed by the transitive verb target (2). 
1a) Baseline prime sentence

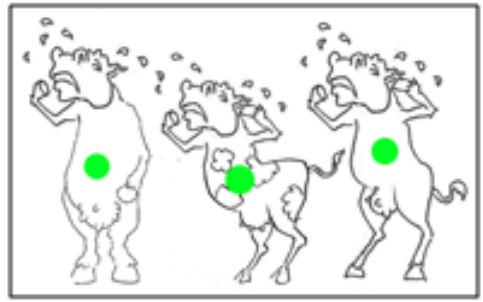

"The cows are crying"

1b) Transitive prime sentence

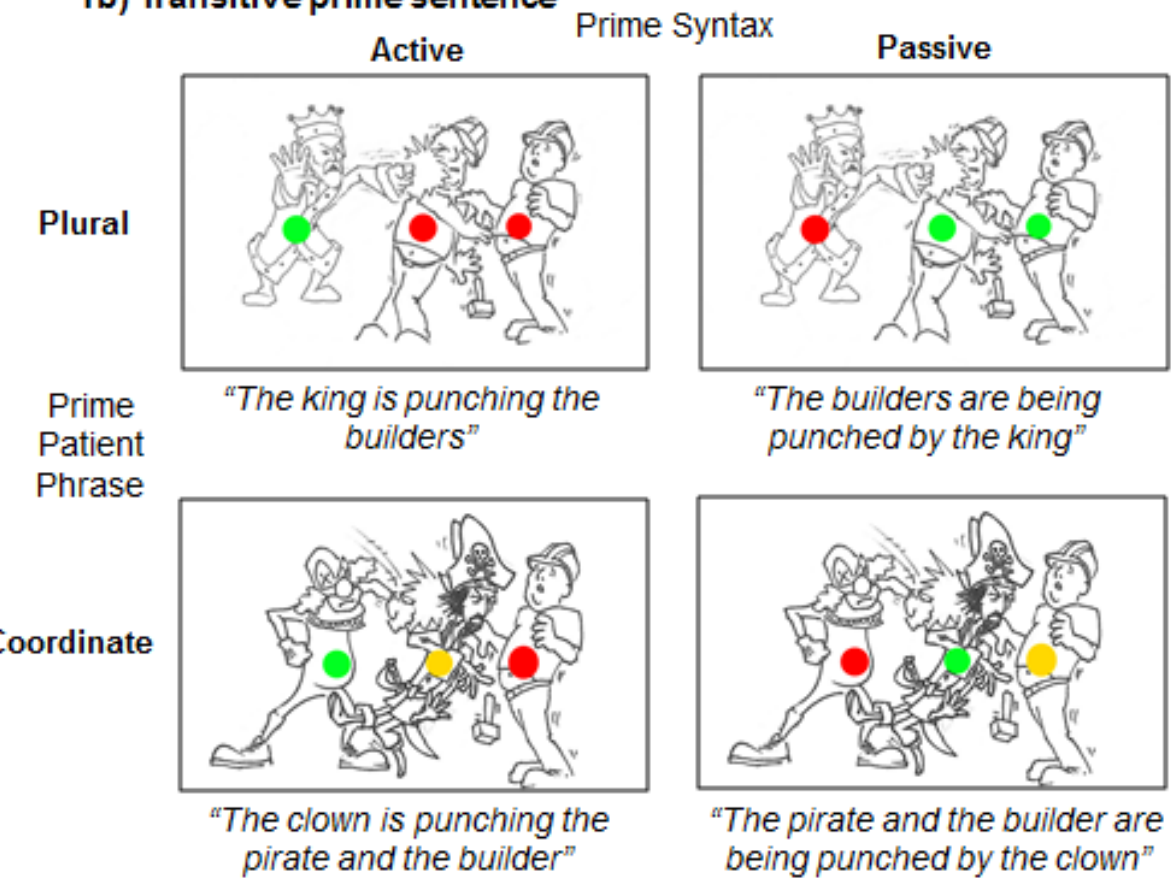

2) Target sentence

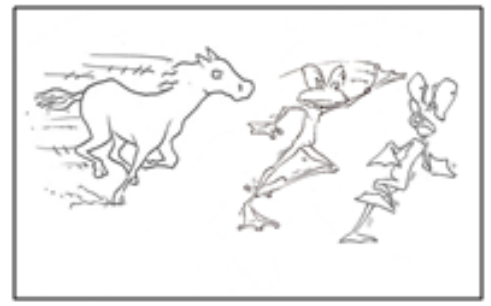

"The horse is chasing the frogs"/

"The frogs are being chased by the horse"

Figure 2. Design of Experiment 1. Prime sentences were elicited using a colour-coding order of precedence system. Baseline primes elicited an intransitive verb sentence (1a). Transitive primes elicited either an active or a passive sentence that contained a plural or coordinate noun phrase structure of the patient role $(1 \mathrm{~b})$. Each prime was followed by a greyscale transitive target that the participant could choose to describe with either an active or a passive sentence that contained the plural morphology of the patient role (2). 
Using a colour-coded system for the order of precedence, we were able to manipulate whether participants produced an active or a passive prime sentence (stoplight paradigm; Menenti, Gierhan, Segaert, \& Hagoort, 2011). We also manipulated whether the patient role of the prime matched that of the target (i.e., also used the plural morphology) or whether the prime patient phrase used a different structure (a coordinate noun phrase). By fully crossing these two manipulations, we created four transitive verb prime conditions (1b) that enabled us to measure the effect of internal constituent noun phrase structure on the magnitude of structural priming in young and older adults.

Materials. The experimental stimuli were based on those previously used by Messenger, Branigan, and McLean (2011), but with significant alterations. A full list of stimuli, including all images, is available to download from the Open Science Framework (https://osf.io/8y5jx/). We first created 16 target pictures that were greyscale in colour and depicted transitive verb events involving one agent acting on two patients of the same type ("The $X$ is verbing the $Y s$ " / "The Ys are being verbed by the $X$ "). The two patients did not look exactly the same (e.g., they had different facial expressions and/or postures), but it was clear that they belonged to the same naming category and occupied the same thematic role within the sentence (see Figure 2). Eight different transitive verbs (chase, hug, ignore, pat, punch, touch, upset and watch) were each used twice to create the 16 target pictures; half of the target pictures featured human nouns, while the other half featured animal nouns. To control for any potential left-right bias, the agents of the action were depicted an equal number of times on the left and right side of the picture.

Using the same transitive verbs, we then created 16 transitive pictures for the 'plural' prime condition and 16 transitive pictures for the 'coordinate' condition (again, half featured human nouns and half featured animal nouns). The 'plural' prime pictures involved one agent acting on two patients of the same type, whereas the 'coordinate' prime pictures depicted one agent acting on two patients of different types. Critically, this meant that the patient role of the prime and the target were matched in the 'plural' condition, but not in the 'coordinate' condition. We then made an active and a passive version of each prime picture using a 'stoplight' colour-coding system. Participants were instructed to describe the characters in a green-red or green-orange-red order; hence, the strategic placements of coloured dots on the characters were used to elicit the prime sentences. For the 'plural' prime pictures, green and 
red dots were used to elicit either an active or a passive sentence that contained the plural morphology of the patient role ("the A is verbing the Cs" / "the Cs are being verbed by the $A$ ”). For the 'coordinate' prime pictures, green, orange and red dots were used to elicit either an active or a passive sentence that contained a coordinate noun phrase of the patient ("the $A$ is verbing the $B$ and the $C$ " / "the $B$ and the $C$ are being verbed by the $A$ "). This created a total of 64 transitive verb primes. We also created 16 baseline primes that depicted intransitive verb events involving three nouns of the same type, all of which were covered with a green dot ("the Ds are verbing"). We then prepared 80 experimental items by combining each of the 16 target pictures with a prime picture from each of the five different prime conditions. Within each experimental item, there was no overlap in the verbs or nouns depicted.

Lastly, we created 16 filler items that were greyscale in colour and depicted intransitive verb events involving three nouns of different types (e.g., "the soldier, the dancer and the king are walking"). Fillers were used to minimise the possibility that participants would notice the priming manipulation. We then constructed five blocks that each contained 16 experimental items (prime plus target pairs) and 16 filler items. Each block contained the same 16 target pictures, but each target was paired with a different prime condition within each block (i.e., each experimental item only appeared once across all five blocks). The same 16 filler items were repeated across the five blocks. The order of the items within each block was pseudorandomised with the constraint that each block must begin with a filler item. The order of the blocks was then rotated to create five experimental lists; this ensured that each block occurred an equal number of times in each position of the experiment.

Procedure and coding. Each participant was randomly assigned to one of the five lists and was tested individually in a quiet testing room. The participant was seated facing a Dell 14 inch laptop, and wore a Sennheiser headset connected to a Cedrus voice key that recorded his/her onset latencies. The presentation of the experiment was controlled using Eprime (Schneider, Eschman, \& Zuccolotto, 2002). Audio responses were recorded using an external Sony digital voice recorder. Before beginning the structural priming task, the participant was presented with the names and pictures of the 34 animal and human characters than would feature in the priming task. The participant was then tested on the names of the different characters. The aim of this was to ensure that the participant was sufficiently 
familiar with the characters and that uncertainty about character names would not negatively impact upon their performance in the main priming task. Participants were told that the characters would appear slightly differently in each trial in the priming task (e.g., different postures or facial expressions), but would always be from one of the 34 naming categories.

Following this, the participant was presented with instructions and examples of how to describe the pictures using the colour-coding system. The participant was instructed to use the verb presented below each picture in their sentence, and to begin describing the picture as soon as possible. Figure 3 illustrates the sequence of stimuli presentation per trial. To begin, there were two practice blocks of 24 pictures each. The practices featured 12 filler pictures, four prime pictures from the baseline condition and eight prime pictures from each of four different transitive verb prime conditions. Crucially, none of these practice prime pictures were followed by a greyscale target picture as we wanted to control the number of actives and passives that the participant produced before beginning the experimental blocks. After the practice, the task continued until all five experimental blocks had been completed.

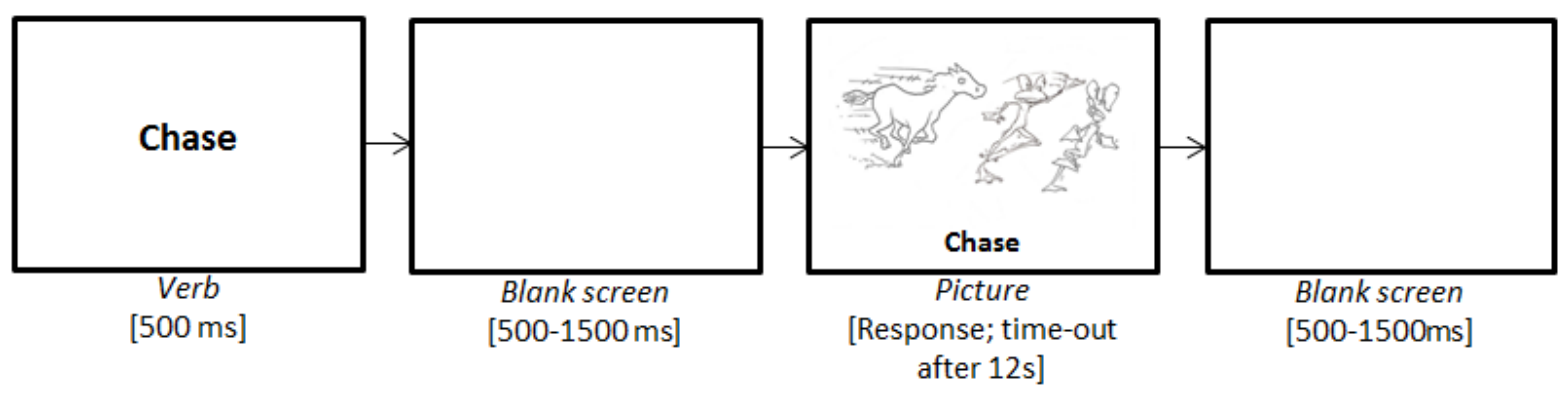

Figure 3. Experiment 1 and 2 stimuli presentation sequence per trial. The sequence presentation event was the same for the prime and target trials, and primes were always immediately followed by the corresponding target. Speech onset latencies on the target trials were recorded from the onset of the picture to when the participant began to speak.

The experimenter manually coded the participant's target responses as either active ("The horse is chasing the frogs") or passive ("The frogs are being chased by the horse"). Target responses were only included in the analyses if the participant produced the correct prime sentence (i.e., according to the colour-coding order of precedence system) and if the following was true of the participant's prime and target responses of the relevant experimental item: (1) the correct verb was used; (2) the description was complete; (3) no 
unnecessary additional information was included; and (4) the participant did not stutter before or during their response.

\section{Experiment 2: Manipulating the Agent Role}

Participants. Forty young adults and 40 older adults were recruited from the same sources and compensated in the same manner described in Experiment 1 (see Table 1). Participants also met the same inclusion criteria and informed written consent was obtained at the beginning of the test session.

Design. The design was identical to Experiment 1, with the only difference being that we now manipulated the noun phrase structure of the agent role (Figure 4).

Materials. We created the prime and target pictures using the same transitive verbs and method described in Experiment 1. The main difference, however, was that the pictures depicted two agents and one patient. The target and 'plural' prime pictures depicted two agents of the same type acting on one patient and could be described using a transitive sentence that contained the plural morphology of the agent role ("the As are verbing the $C$ " / "the C is being verbed by the As"). The 'coordinate' prime pictures contained two agents of different types acting on one patient and could be described using an transitive sentence that contained a coordinate noun phrase of the agent ("the $A$ and $B$ are verbing the $C$ " / "the $C$ is being verbed by the $A$ and the B"). We used the same intransitive baseline pictures ("the Ds are verbing") as Experiment 1. Following the method in Experiment 1, we then created 80 experimental items. Lastly, using the same filler items as Experiment 1, we constructed five blocks that each contained 16 experimental items (prime plus target pairs) and 16 filler items, and rotated the order of the blocks to create five experimental lists.

Procedure and coding. The experimental procedure and coding criteria were identical to Experiment 1 . The only difference was that correct target responses must feature the plural morphology of the agent phrase (e.g., "The horses are chasing the frog" / "The frog is being chased by the horses"). 
1a) Baseline prime sentence

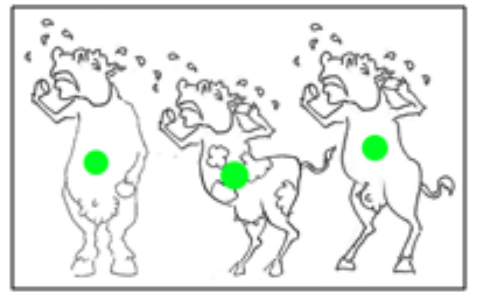

"The cows are crying"

1b) Transitive prime sentence

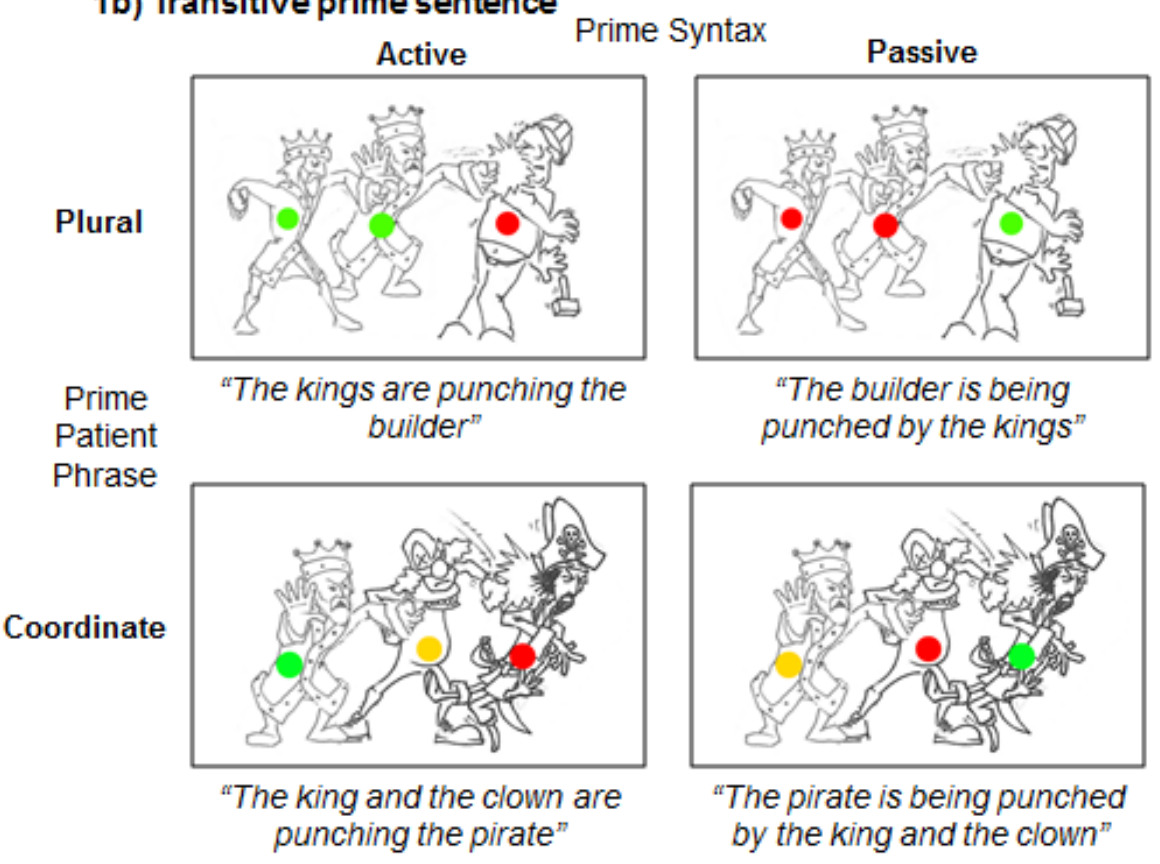

2) Target sentence

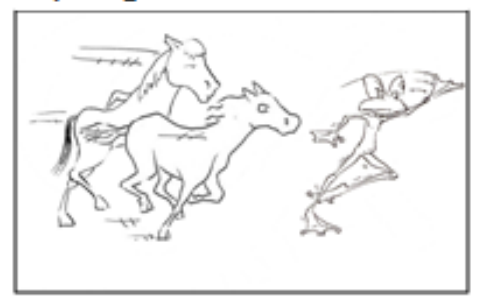

"The horses are chasing the frog"/ "The frog is being chased by the horses"

Figure 4. Design of Experiment 2. Prime sentences were elicited using a colour-coding order of precedence system. Baseline primes elicited an intransitive verb sentence (1a). Transitive primes elicited either an active or a passive sentence that contained a plural or coordinate structure of the agent role (1b). Each prime was followed by a greyscale transitive target that the participant could choose to describe with either an active or a passive sentence that contained the plural morphology of the agent role (2). 


\section{Data Preparation and Analyses}

Analysis of the choice priming data. In total we recorded 6400 target responses each for Experiments 1 and 2. As is standard in structural priming studies, we first excluded targets for which the corresponding prime was incorrect (i.e., when the participant did not produce an active or passive prime sentence that adhered to colour-coding order of precedence system). This resulted in the discarding of $66(2.1 \%)$ and 171(5.3\%) of young and older adults' target responses in Experiment 1, and 191 (6.0\%) and 275 (8.6\%) of young and older adults' responses in Experiment 2. Next, we excluded target responses for which the participant made an error. A target response was defined as containing an error if: (1) the lexical items were named incorrectly; (2) a different verb was used to the one written beneath the picture; (3) a different syntactic structure was used (i.e., not a complete active or passive sentence); or (4) the participant stuttered before or during their response. In Experiment 1, this resulted in the exclusion of 189 (6.0\%) of the young adults' target responses, and 318 $(10.5 \%)$ of the older adults' responses. In Experiment 2, this resulted in the exclusion of 182 $(6.0 \%)$ and $230(8.2 \%)$ young and older adults' responses, respectively. Thus, there remained 5656 and 5513 analysable target responses in Experiments 1 and 2, respectively.

The data from the two experiments were analysed separately because the target items were not identical across experiments (i.e., they varied in terms of the number of agents and patients); however, we did follow the same method of analysis. Target responses were coded as 0 for actives and 1 for passives, and we analysed the data using a logit mixed-effects model with the lme4 package (Bates, Mächler, Bolker, \& Walker, 2014) in R (R Core Team, 2015). This is the most suitable way to analyse the data as the dependent variable was categorical (active or passive) and there were repeated observations for participants and items (Baayen, Davidson, \& Bates, 2008; Barr, Levy, Scheepers, \& Tily, 2013; Jaeger, 2008). We used a maximal random effects structure as this allowed us to include per-participant and peritem adjustments to the fixed interprets (random intercepts) with additional random adjustments to the fixed effects (random slopes).

To examine the effect of structural priming, it is necessary to compare syntactic choices in the different transitive verb priming conditions to the baseline condition (Segaert et al., 2011, 2014, 2016). Using treatment contrast coding, we therefore entered 'Prime Condition' as a fixed effect into the model - this contained five levels in which the baseline 
condition was the reference level (i.e., included in the intercept of the model), and the four transitive verb prime conditions were directly compared to the baseline condition. To further assess the statistical differences between the Passive Plural and Passive Coordinate conditions, we refitted the model with Passive Coordinate as the reference level. We also entered age group (young vs. old) into the model as a fixed effect, which we sum-coded and transformed to have a mean of 0 and a range of 1 prior to analysis. In each model, we included random intercepts for participants and items, as well as by-participant random slopes for within-participant fixed effects and by-item random slopes for within-item fixed effects. When a model did not converge with the maximal random effects structure, we simplified the random slopes, removing interactions before main effects in the order of least variance explained until the model converged (Barr et al., 2013).

Analysis of the onset latency priming data. One young adult and two older adults in Experiment 1 were excluded from the onset latency analysis due to technical issues with the voicekey that meant no latency data were recorded. All baseline responses were also excluded as we were specifically interested in the effect of active and passive primes on the onset latencies of active and passive target responses. We excluded individual target responses for which the voicekey was not triggered (discarding 83 (3.6\%) and $256(12.6 \%)$ of young and older adults' responses in Experiment 1, and 69 (3.1\%) and 219 (10.4\%) of young and older adults' responses in Experiment 2). ${ }^{2}$ We further excluded target responses for which the speech onset latency was below $300 \mathrm{~ms}$, above $4000 \mathrm{~ms}$ or more than 2.5SDs above/below each participant's mean per condition (discarding 56 (2.5\%) and 61 (3.4\%) of young and older adults' responses in Experiment 1, and 63 (2.9\%) and 55 (2.9\%) of young and older adults' responses in Experiment 2). This resulted in a total of 3863 and 3930 analysable targets responses in Experiments 1 and 2, respectively.

In order to examine the effect of syntactic priming on onset latencies, it was necessary to create a post-hoc variable of 'Syntactic Repetition' with two levels of No Repetition and Syntactic Repetition. The variable captured the relationship between the prime syntactic structure (active or passive) and the chosen structure of the target response (active or

\footnotetext{
${ }^{2}$ We speculate that the large number of older adult responses in which the voicekey was not triggered may have been caused by the larger variation in speech volume, frequency and onset typically seen in older adults (Benjamin, 1981; Hooper \& Cralidis, 2009; Morris \& Brown, 1994).
} 
passive), such that each prime and target pair could either be coded in the No Repetition or Syntactic Repetition condition.

The onset latency data were again analysed in $\mathrm{R}$ using the lme4 package (Bates et al., 2014). As the dependent variable was continuous, we used a linear mixed-effects model with a maximal random effects structure (as recommended for our design; Baayen et al., 2008; Barr et al., 2013; Jaeger, 2008). For Experiments 1 and 2, we entered age group (young vs. old), prime phrase type of the agent or patient role (plural vs. coordinate), target structure (active vs. passive) and syntactic repetition (no repetition vs. syntactic repetition) as fixed effects into the model. Prior to analysis, all fixed effects were sum-coded and transformed to have a mean of 0 and a range of 1 . For both models, we included random intercepts for participants and items, as well as by-participant random slopes for the within-participant fixed effects and by-item random slopes for the within-item fixed effects. When a model did not converge with the maximal random effects structure, we simplified the random slopes following the same method outlined in the analysis of the choice priming data. Significance $p$ values were calculated using the car package (Fox \& Weisberg, 2011). 


\section{Results}

\section{Examining the Effect of the Prime Phrasal Structure on Choice Structural Priming} Manipulating the prime phrasal structure of the patient role. The proportion of passive responses produced by participants in the different prime conditions in Experiment 1, in which we manipulated the prime noun phrase structure relating to the patient role, is shown in Figure 5A and the final model of the choice data is summarised in Table 2A.

Firstly, the negative intercept of the model indicates that actives were produced more often than passives in the baseline condition (11.8\% baseline passive responses). However, as can clearly be seen in Figure 5A, there was a significant increase in the proportion of target passives produced, compared to baseline, in both the Passive Plural (19.8\% passives, $p<$ $.001)$ and Passive Coordinate (17.8\% passives, $p<.001)$ conditions. By contrast, the proportion of passives produced was not significantly different from baseline in the Active Plural (10.9\% passives, $p=.591)$ and Active Coordinate $(11.2 \%$ passives, $p=.889)$ prime conditions. This is evidence of the inverse preference effect: syntactic choices are affected by passive, but not active, primes.

To now consider the effect of manipulating the prime patient phrase on choice structural priming, we predicted that, if the internal constituent phrasal structure of the prime was a factor in choice structural priming, then we would observe greater priming in the Passive Plural condition (in which the subject phrasal structure of the prime matched the target) compared to the Passive Coordinate condition (in which the subject phrase of the prime was different to the target). However, we found instead that the proportion of passives produced was not significantly different in the Passive Plural condition compared to the Passive Coordinate condition (Coefficient $=0.08, z=0.54, p=.586$ ). Syntactic choices were therefore unaffected by whether the constituent phrasal structure of the patient role was matched or mismatched between the prime and target.

Manipulating the prime phrasal structure of the agent role. The proportion of passive responses produced by participants in the different prime conditions in Experiment 2, in which we manipulated the prime noun phrase structure relating to the agent role, is shown in Figure 5B and the final model of the choice data is summarised in Table 2B.

Similar to Experiment 1, we found that more actives than passives were produced in the baseline condition ( $15.8 \%$ passives, negative intercept the model). We also found 
evidence of the inverse preference effect: compared to baseline, syntactic choices were significantly affected by passive primes (Passive Plural, 25.7\% passives, $p<.001$; Passive Coordinate, $24.3 \%$ passives, $p<.001$ ), but were not affected by active primes (Active Plural, $13.6 \%$ passives, $p=.082$; Active Coordinate, $14.6 \%$ passives, $p=.446)$. Moreover, the proportion of passives produced was not significantly different when comparing the Passive Plural and Passive Coordinate prime conditions (Coefficient $=0.01, z=0.15, p=.975$ ). This replicates the findings of Experiment 1, and demonstrates that the invariant effect of prime phrase structure persists even when the more thematically salient agent phrase is manipulated.

Examining the effect of age group on choice structural priming. In the choice data analysis of Experiments 1 and 2, we found no main effect of age group or any interactions involving age group and prime condition (all $p$ s $<.2$; Tables $2 \mathrm{~A}$ and $2 \mathrm{~B}$ ). This would indicate that young and older adults were experiencing similar choice structural priming effects. Indeed, the pattern of target passives in the different prime conditions appears similar in both age groups for Experiments 1 and 2 (Figure 6).

As the effect of age group was critical to our research question, we sought to confirm the similar patterns in young and older adults by modelling the choice data separately for each age and experiment group. We followed the same procedure as described previously: the final models of the choice data for each participant group are summarised in Table 3. Compared to baseline, both age groups in Experiments 1 and 2 produced significantly more target passives following passive primes (all $p s<.04$ ), as can clearly be seen in Figure 6. Moreover, there was no difference in the proportion of passives produced between the Passive Plural and Passive Coordinate prime conditions for both age groups in Experiment 1 (Young, Coefficient $=0.11, z=0.20, p=.567$; Older, Coefficient $=-0.04, z=-0.19, p=.849$ ) and Experiment 2 (Young, Coefficient $=0.08, z=0.43, p=.669$; Older, Coefficient $=-0.07, z$ $=-0.38, p=.707)$. The findings from Experiments 1 and 2 therefore demonstrate that structural priming effects persist with old age, and that neither young nor older adults' primed production of passive sentences were affected by whether the prime constituent phrasal structure matches or mismatches that of the target. 

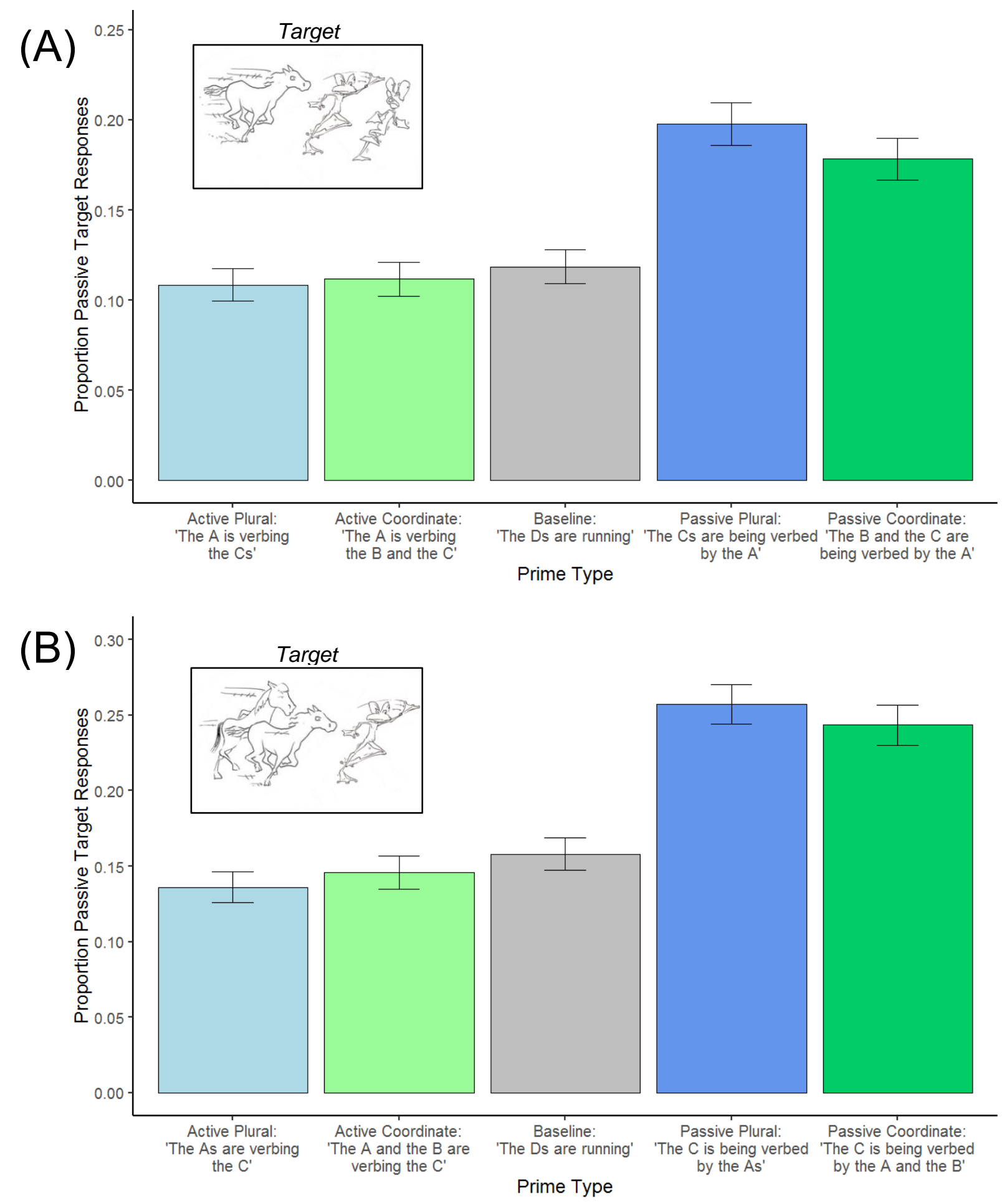

Figure 5. Mean proportion of passive responses produced by participants following the five different prime conditions in Experiment $1(A)$ and Experiment $2(B)$. Error bars denote \pm 1 the standard error of the mean. In both experiments, compared to baseline, participants were significantly more likely to produce a passive target following a passive prime, but not following an active prime. Moreover, syntactic choices were affected equally when the prime and the target contained the same or different internal phrasal structure (passive plural vs. passive coordinate conditions). 

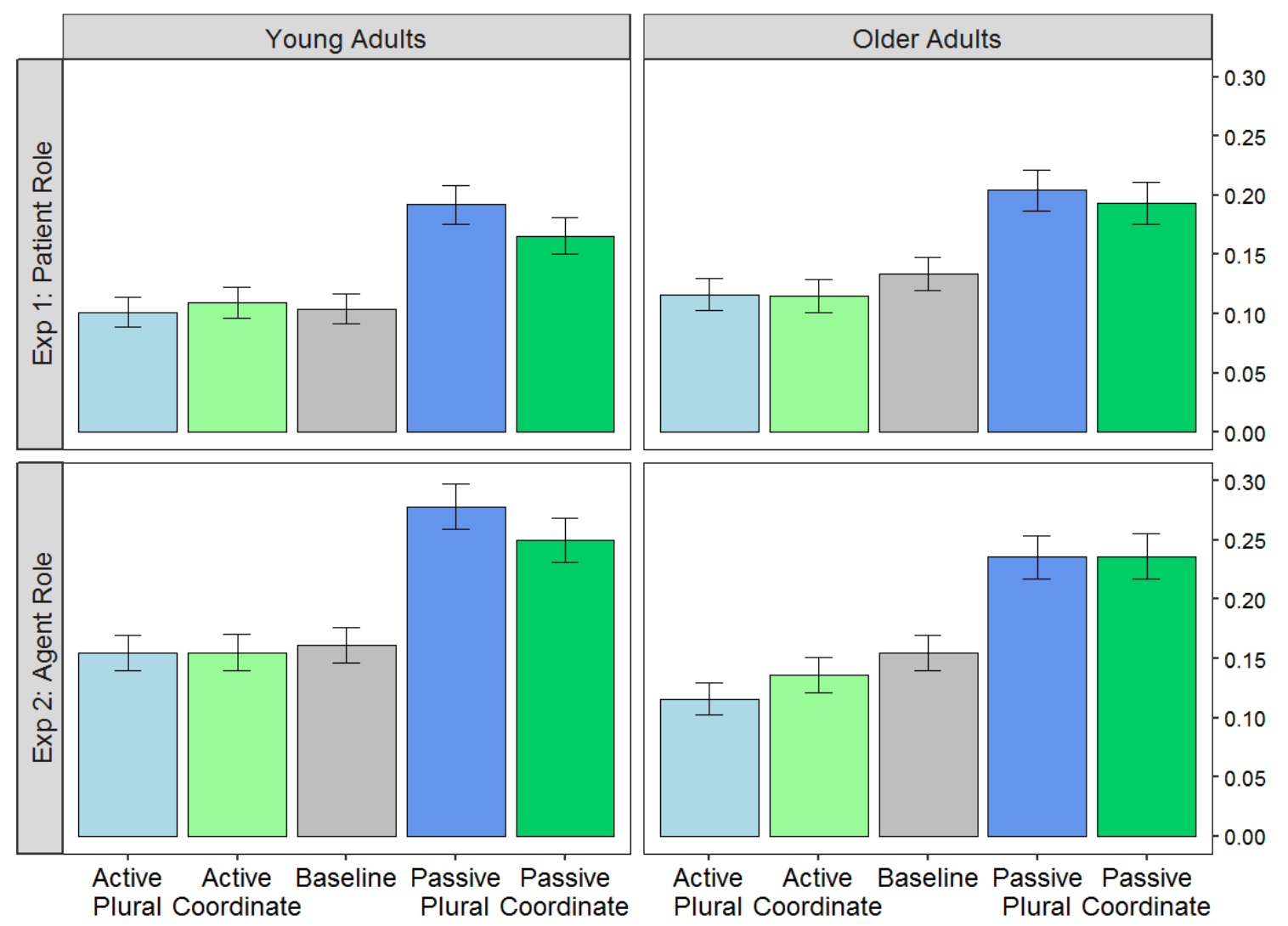

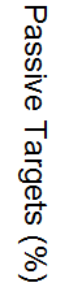

Figure 6. Mean proportion of passive responses produced by young and older adults

following the different prime conditions in Experiment 1 (manipulating the patient role) and Experiment 2 (manipulating the agent role). Error bars denote \pm 1 the standard error of the mean. In all groups, there was significant priming of passives compared to baseline in both the Passive Plural and Passive Coordinate prime conditions. 
Table 2. Summary of the best-fitted mixed-effects models for the choice data of Experiments 1 and 2.

\begin{tabular}{|c|c|c|c|c|}
\hline Predictor & Coefficient & $\mathrm{SE}$ & Wald Z & $p$ \\
\hline \multicolumn{5}{|l|}{ A: Experiment 1} \\
\hline Intercept (Baseline) & -2.66 & 0.25 & -10.43 & $<.001$ \\
\hline Active Plural Prime & -0.08 & 0.16 & -0.54 & .591 \\
\hline Active Coordinate Prime & -0.02 & 0.25 & -0.14 & .889 \\
\hline Passive Plural Prime & 0.72 & 0.14 & 4.98 & $<.001$ \\
\hline Passive Coordinate Prime & 0.65 & 0.14 & 4.53 & $<.001$ \\
\hline Age Group & -0.28 & 0.35 & -0.80 & .426 \\
\hline Active Plural Prime * Age Group & 0.24 & 0.29 & 0.85 & .394 \\
\hline Active Coordinate Prime * Age Group & 0.31 & 0.29 & 1.09 & .227 \\
\hline Passive Plural Prime * Age Group & 0.28 & 0.26 & 1.06 & .290 \\
\hline Passive Coordinate Prime * Age Group & 0.13 & 0.27 & 0.48 & .634 \\
\hline \multicolumn{5}{|l|}{ B: Experiment 2} \\
\hline Intercept (Baseline) & -2.13 & 0.23 & -9.14 & $<.001$ \\
\hline Active Plural Prime & -0.28 & 0.16 & -1.74 & .082 \\
\hline Active Coordinate Prime & -0.14 & 0.19 & -0.76 & .446 \\
\hline Passive Plural Prime & 0.62 & 0.16 & 3.99 & $<.001$ \\
\hline Passive Coordinate Prime & 0.63 & 0.15 & 4.11 & $<.001$ \\
\hline Age Group & 0.03 & 0.30 & 0.09 & .936 \\
\hline Active Plural Prime * Age Group & 0.33 & 0.26 & 1.27 & .204 \\
\hline Active Coordinate Prime * Age Group & 0.12 & 0.26 & 0.47 & .641 \\
\hline Passive Plural Prime * Age Group & 0.23 & 0.24 & 0.97 & .331 \\
\hline Passive Coordinate Prime * Age Group & 0.03 & 0.24 & 0.14 & .889 \\
\hline
\end{tabular}

Note. Both models converged with random intercepts for participants and items with an additional byitem random slope for the main effect of prime condition. We also analysed the choice priming data without the baseline condition (instead entering prime syntax and prime phrase type as fixed effects) as this matches the approach used in most other priming studies (see Mahowald et al., 2016). This produced results in line with our primary modelling analysis of Experiments 1 and 2; specifically, we found main effects of prime syntax $(p s<.001)$, but not of prime phrase type $(p s>.15)$ or any interactions between the two variables $(p s>.15)$. 
Table 3. Summary of the best-fitted mixed-effects models for young and older adults' choice data in Experiments 1 and 2.

\begin{tabular}{lcccc}
\hline Predictor & Coefficient & SE & Wald Z & $p$ \\
\hline A: Young Adults Experiment 1 & & & & \\
\hline Intercept (Baseline) & -2.65 & 0.25 & -10.49 & $<.001$ \\
Active Plural Prime & -0.02 & 0.22 & -0.11 & .912 \\
Active Coordinate Prime & 0.004 & 0.23 & 0.02 & .983 \\
Passive Plural Prime & 0.74 & 0.22 & 3.30 & $<.001$ \\
Passive Coordinate Prime & 0.63 & 0.20 & 3.22 & .001 \\
\hline B: Older Adults Experiment 1 & & & & \\
\hline Intercept (Baseline) & -2.75 & 0.39 & -6.97 & $<.001$ \\
Active Plural Prime & -0.14 & 0.23 & -0.61 & .540 \\
Active Coordinate Prime & -0.09 & 0.24 & -0.36 & .716 \\
Passive Plural Prime & 0.60 & 0.23 & 2.61 & .009 \\
Passive Coordinate Prime & 0.64 & 0.21 & 3.07 & .002 \\
\hline C: Young Adults Experiment 2 & -2.07 & 0.25 & -8.30 & $<.001$ \\
\hline Intercept (Baseline) & -0.48 & 0.22 & -2.21 & .027 \\
Active Plural Prime & -0.28 & 0.23 & -1.23 & .218 \\
Active Coordinate Prime & 0.46 & 0.22 & 2.09 & .036 \\
Passive Plural Prime & -2.25 & 0.34 & -6.58 & $<.001$ \\
Passive Coordinate Prime & -0.05 & 0.23 & -0.22 & .829 \\
\hline D: Older Adults Experiment 2 & 0.08 & 0.26 & 0.30 & .764 \\
\hline Intercept (Baseline) & 0.86 & 0.22 & 3.91 & $<.001$ \\
Active Plural Prime & 0.20 & 2.67 & .008 \\
Active Coordinate Prime & & 0.24 & .001 \\
Passive Plural Prime & & & & \\
Passive Coordinate Prime & & & & \\
\hline Ant & & & & \\
\hline
\end{tabular}

Note. All models converged with random intercepts for participants and items with an additional byitem random slope for the main effect of prime condition. 


\section{Examining Onset Latency Structural Priming Effects}

The effect of syntactic repetition on the onset latencies of active and passive target responses in Experiments 1 and 2 is shown in Figure 7. The best-fitting model of the onset latency priming data is summarised in Table 4 for both experiments.

As expected, we found that young adults' speed of sentence production was quicker overall than older adults in both experiments $(p s<.001) .{ }^{3}$ We also found a main effect of target structure (Experiment 1, $p<.001$; Experiment 2, $p=.003$ ), such that actives were produced significantly quicker overall than passives, as can be clearly seen in Figure 7. In Experiment 1, we found a main effect of syntactic repetition $(p=.021)$, such that target responses were produced quicker following primes of the same structure. However, we did not find an interaction between target structure and syntactic repetition $(p=.310)$, as we has expected to if latency priming effects were greater for actives than passives (Segaert et al., 2011, 2016). In Experiment 2, although there was a trend toward an effect of syntactic repetition on target onset latencies, this effect did not pass the significance threshold $(p=$ .073). Likewise, we did not observe any interaction between target structure and syntactic repetition in Experiment $2(p=.835)$.

To now consider the effect of prime phrase type (coordinate vs. plural noun phrase structure) on target onset latencies, we found minimal effects in both experiments. Although the interaction between target structure, syntactic repetition and prime phrase type just reached significant in Experiment $1(p=.049)$, post-hoc analyses revealed that the interaction between syntactic repetition and prime phrase type was not significant for the production of either active $\left(\chi^{2}(1)=0.24, p=.625\right)$ or passive $\left(\chi^{2}(1)=3.22, p=.072\right)$ targets. ${ }^{4}$ This suggests that the onset latency priming of actives and passives was not significantly different when the prime and target structure contained the same phrasal structure of the patient role

\footnotetext{
${ }^{3}$ Due to the large speed differences between young and older adults, we also performed the modelling analysis with age-standardised onset latencies (using z-score adjustments within age groups). This produced the same effects (expect for the main effect of age) seen in the non-adjusted onset latencies analyses for both Experiments 1 and 2.

${ }^{4}$ The 'testInteractions' function in the phia package (de Rosario-Martinez, 2015) allows for the direct comparison of the contrasts specified within mixed-effects models. This can be used to investigate the nature of the interactions between the variables entered into the model as fixed effects.
} 
(plural condition) or a different phrasal structure (coordinate condition). Similarly, we did not find any effects or interactions involving prime phrase type in Experiment 2 (all $p s>.25$ ). Finally, we observed no significant interactions involving age group in either experiment (all $p s<.2)$.

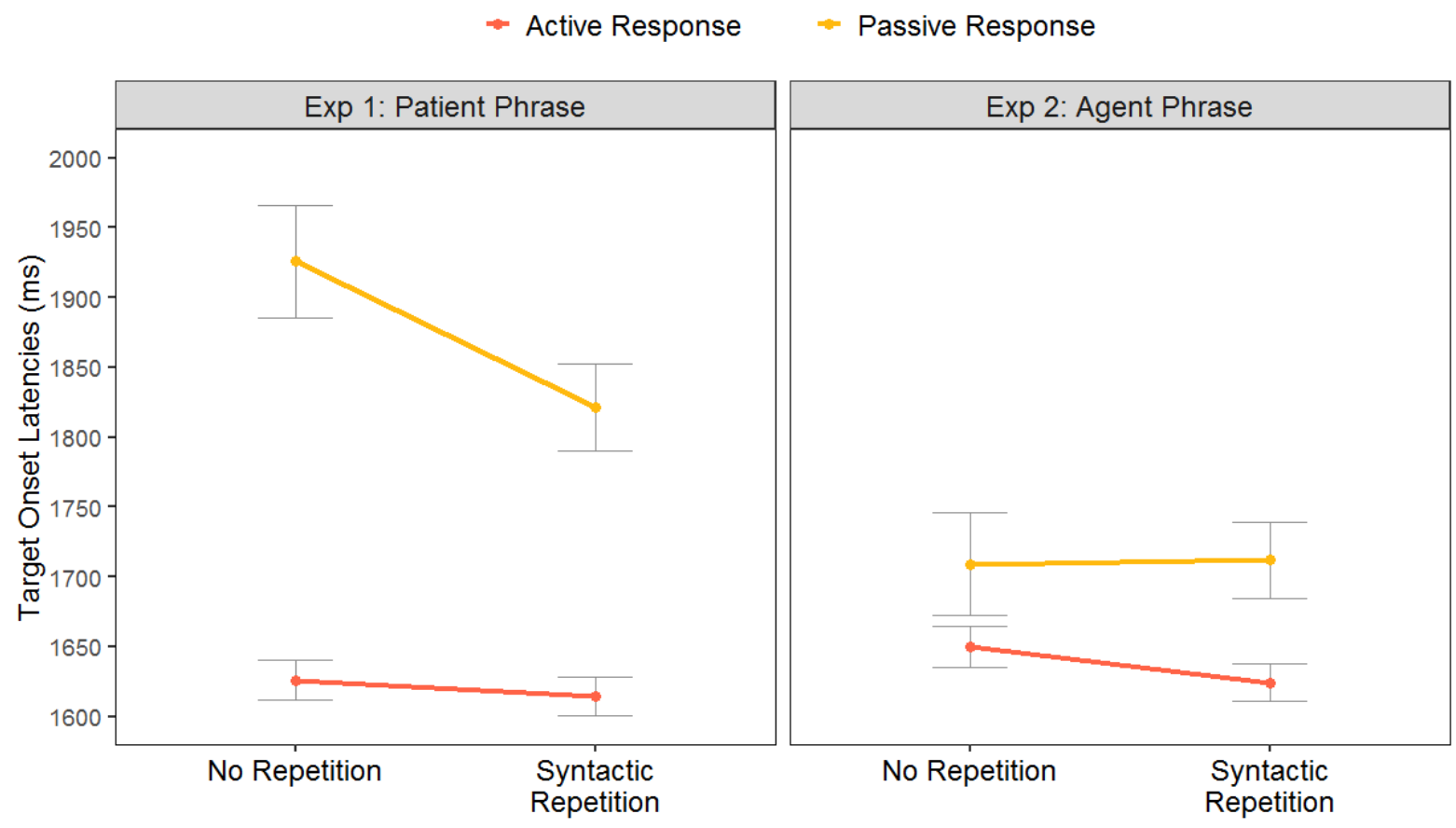

Figure 7. Mean target onset latencies collapsed across age group and prime phrasal structure for Experiments 1 and 2. Error bars denote \pm 1 the standard error of the mean. In both experiments, active targets were produced significantly quicker than passive targets, and there was a trend toward structural priming of onset latencies (target responses produced quicker following primes of the same structure). 
Table 4. Summary of the best-fitted mixed-effects models for the onset latency data in Experiments 1 and 2.

\begin{tabular}{|c|c|c|c|c|}
\hline Predictor & Coefficient & $\mathrm{SE}$ & $t$-value & $p$ \\
\hline \multicolumn{5}{|l|}{ A: Experiment 1} \\
\hline Intercept & 1810.80 & 43.38 & 41.75 & $<.001$ \\
\hline Age Group & -536.91 & 74.86 & -7.17 & $<.001$ \\
\hline Target Structure & 204.24 & 44.62 & 4.58 & $<.001$ \\
\hline Syntactic Repetition & -48.99 & 21.38 & -2.29 & .021 \\
\hline Prime Phrase Type & 25.88 & 22.80 & 1.14 & .134 \\
\hline Age Group * Target Structure & 5.89 & 64.73 & 0.09 & .751 \\
\hline Age Group * Syntactic Repetition & 25.96 & 42.82 & 0.61 & .581 \\
\hline Age Group * Prime Phrase Type & -5.62 & 41.02 & -0.14 & .242 \\
\hline Target Structure * Syntactic Repetition & -44.08 & 40.90 & -1.08 & .310 \\
\hline Target Structure * Prime Phrase Type & -9.50 & 40.81 & -0.23 & .524 \\
\hline Syntactic Repetition * Prime Phrase Type & -61.36 & 40.67 & -1.51 & .961 \\
\hline \multicolumn{5}{|l|}{ Age Group * Target Structure } \\
\hline * Syntactic Repetition & 113.29 & 82.00 & 1.38 & .175 \\
\hline \multicolumn{5}{|l|}{ Age Group * Target Structure } \\
\hline * Prime Phrase Type & 73.18 & 81.29 & 0.90 & .498 \\
\hline \multicolumn{5}{|l|}{ Age Group * Syntactic Repetition } \\
\hline * Prime Phrase Type & -9.93 & 81.38 & -0.12 & .331 \\
\hline \multicolumn{5}{|l|}{ Target Structure $*$ Syntactic Repetition * } \\
\hline Prime Phrase Type & -150.71 & 81.23 & -1.86 & .049 \\
\hline \multicolumn{5}{|l|}{ Age Group * Target Structure } \\
\hline * Syntactic Repetition * Prime Phrase Type & -164.50 & 162.54 & -1.01 & .312 \\
\hline \multicolumn{5}{|l|}{$B:$ Experiment 2} \\
\hline Intercept & 1756.06 & 43.65 & 40.23 & $<.001$ \\
\hline Age Group & -544.20 & 70.04 & -7.77 & $<.001$ \\
\hline Target Structure & 114.53 & 38.84 & 2.95 & .003 \\
\hline Syntactic Repetition & -27.95 & 21.52 & -1.30 & .073 \\
\hline Prime Phrase Type & -10.73 & 19.46 & -0.55 & .597 \\
\hline Age Group * Target Structure & -16.59 & 56.72 & -0.29 & .683 \\
\hline Age Group * Syntactic Repetition & -13.86 & 36.83 & -0.38 & .996 \\
\hline
\end{tabular}


Age Group * Prime Phrase Type

Target Structure * Syntactic Repetition

Target Structure * Prime Phrase Type

Syntactic Repetition* Prime Phrase Type

Age Group * Target Structure

* Syntactic Repetition

Age Group * Target Structure

* Prime Phrase Type

Age Group * Syntactic Repetition

* Prime Phrase Type

Target Structure * Syntactic Repetition *

Prime Phrase Type

Age Group * Target Structure

* Syntactic Repetition * Prime Phrase Type
42.13

10.08

36.30

1.16

.407

$-0.92$

37.05

0.27

.835

19.18

36.56

$-0.03$

.986

$\begin{array}{lll}36.31 & 0.53 \quad .304\end{array}$

$-41.91$

73.41

$-0.57$

.559

$\begin{array}{llll}69.54 & 72.71 & 0.96 & .254\end{array}$

$\begin{array}{llll}35.88 & 72.40 & 0.50 & .810\end{array}$

$\begin{array}{llll}-22.46 & 72.47 & -0.31 & .814\end{array}$

$\begin{array}{lll}68.64 & 144.68 & 0.47\end{array}$

.635

Note. The Experiment 1 model converged with random intercepts for participants and items with additional by-participant random slopes for the main effects of target structure, prime phrase type and syntactic repetition, and by-item random slopes for the main effects of target structure, prime phrase type and age group. The Experiment 2 model converged with random intercepts for participant and items with an additional by-participant random slope of the main effect of target structure, and additional by-item random slopes of all main effects. 


\section{Discussion}

Using a structural priming paradigm, we investigated the effect of constituent phrasal structure on primed syntactic choices and sentence planning in young and older adults. Our study has three main findings. First, the magnitude of the priming effect on syntactic choices was unaffected by whether the prime and target contained the same or different constituent noun phrase structure in both Experiment 1 (in which we manipulated the phrasal structure of the patient role) and Experiment 2 (in which we manipulated the phrasal structure of the agent role). This suggests that primed syntactic choices are determined by highly abstract representations of the global syntactic structure that are unspecified for constituent phrasal properties, as predicted by both residual activation and implicit learning models of structural priming (Chang et al., 2006; Pickering \& Branigan, 1998). Second, we found that all syntactic choice priming effects were similar for young and older participants (i.e., there were no significant differences between age groups). This indicates an age-related preservation of the mechanisms that support choice structural priming and syntax selection across the lifespan. Third, there was a trend toward structural priming in participants' speech onset latencies (i.e., speakers initiated target sentences quicker when the structure was repeated across the prime and target); however, in contrast to the predictions of the two-stage competition model (Segaert et al., 2016) and accounts of incremental planning (Wheeldon, 2013), the magnitude of the latency priming effects were not affected by the target syntactic structure or by repetition of the initial phrase structure.

To first consider the priming effects on syntactic choices, we found robust evidence of the inverse preference effect: there was a significant priming effect for passives (i.e., compared to the baseline condition, speakers produced significantly more passive responses following passive primes), but not for actives, replicating previous production studies (Mahowald et al., 2016). Critically though, our study is the first to demonstrate that choice structural effects persist in equal magnitude when the complexity of the noun phrase structure differs between the prime and target (specifically, when the prime contains a coordinate noun phrase structure, but the target contains a plural noun phrase). Our findings therefore support a model of structural priming in which a syntactic structure is represented in a highly abstract form consisting only of the global relationship between grammatical phrases, but which is unspecified for the internal features within the constituent phrases (i.e., the representation of a 
passive sentence relates to the broader prepositional by-phrase structure, but the features within the constituent noun phrases are unspecified). This is consistent with both a residual activation account of structural priming which proposed that combinatorial nodes representing syntax within the lexicon only encompass the critical global syntactic structure relating to the transitive verb (Pickering \& Branigan, 1998), and an implicit learning account which specifies that the sequence of words within a noun phrase does not affect the broader syntactic representation (Chang et al., 2000, 2006). Indeed, Chang and colleagues claim that this feature is crucial for ensuring optimal efficiency with the language processing network, and that complete syntactic representations can still be activated using missing, but implied, elements (e.g., short passives with an implicit agent; Messenger et al., 2011). Applied to our findings, this suggests that participants encoded the prime syntactic structure within the same abstract representation regardless of whether it consisted of a plural or coordinate noun phrase structure, thus enabling both prime phrase types to equally prime production of a target sentence containing a plural noun phrase structure.

Notably, we found similar choice structural priming effects when we manipulated the noun phrase structure related to both the patient role (Experiment 1) and the agent role (Experiment 2). This is important because it enables us to rule out alternative explanations for our findings relating to conceptual salience and syntactic order. Specifically, the invariant effect of prime phrase type we observed in Experiment 1 cannot be explained by the fact that the patient role (relating to the recipient of the action) may not be conceptually salient enough for changes to the noun phrase structure to affect how syntactic representations are encoded. This is because we observed similar effects in Experiment 2, in which we manipulated the noun phrase structure of the agent role (relating to the more thematically important doer of the action). Likewise, the effects we observed in Experiment 2 cannot be solely attributed to the repetition of initial phrase structure as, if this was the case, we would have expected to observe less passive priming in the Passive Coordinate prime condition in Experiment 1 in which the initial phrase structure was not repeated between the prime and target. Thus, taking both experiments together, our findings indicate that the saliency of thematic role does not affect the encoding of the global syntactic structure of the prime and that the content of the initial phrase is not more heavily weighted when a speaker is choosing whether to use an active or a passive sentence to describe the target. Our study therefore adds to the growing 
evidence that changes to the internal properties of a sentence, at least at the non-head lexical item level, do not affect structural priming as long as the global syntactic structure remains the same (e.g., Bock, 1989; Fox Tree \& Meijer, 1999; Pickering \& Branigan, 1998). Importantly, we demonstrated this effect without needing to include additional thematic information when manipulating the open-class content between the prime and target (i.e., all primes and targets conveyed the same thematic event and featured the same number of agents/patients). This is unlike previous studies that have included additional descriptive information relating to the overall thematic event when manipulating the open-class content of the prime and target, either in the form of adjectives (Pickering \& Branigan, 1998) or embedded/subordinate clauses (Branigan et al., 2006; Fox Tree \& Meijer, 1999). As such, our study provides more decisive evidence that, when the application of a global syntactic structure can be repeated, structural priming effects occur regardless of internal phrasal structure rules that could also be applied.

It is important to note that our findings specifically relate to changes in the internal structure of a non-head noun phrase (i.e., in a transitive verb sentence, it is the verb phrase that corresponds to the head lexical item). In alternative sentence structures in which the noun is the head lexical item, it remains possible that changes to the internal noun phrase structure may have a greater effect on the magnitude of structural priming because, according to the residual activation model, an individual lemma node exists for the head lexical item that is activated in conjunction with the combinatorial node (Pickering \& Branigan, 1998).

However, such a prediction is not supported by the implicit learning model, which instead predicts that changes to the internal phrasal structure of both head and non-head lexical items should not affect syntactic choices because global syntactic representations are unspecified for the internal sequence of words within all constituent phrases (Chang et al., 2006). Such shallow processing of the internal phrasal structure draws certain parallels with the 'goodenough' account of sentence processing (Ferreira, Bailey, \& Ferraro, 2002; Ferreira \& Patson, 2007): in an attempt to minimise processing load, language users may generate superficial representations of sentences that do not include all constituent features (e.g., whether the noun phrase consists of a plural or coordinate structure). Nevertheless, compared to comprehension, such superficial processing is considerably less likely in situations in which speakers must generate the sentence themselves as they must correctly plan and 
produce each individual word (Levelt, 1989). As such, in the production-to-production paradigm we used, it is likely that speakers still fully processed the phrasal structure of the prime, but that this information was not encoded within the global syntactic representation.

Applied to sentence production more generally, our robust finding of an invariant effect of prime phrase type on syntactic choices supports a model of sentence generation whereby thematic representations of the message are first assigned syntactic roles (e.g., patient to subject, and agent to object), which then drives the generation of the complete syntactic structure (e.g., a passive sentence) (Bock \& Levelt, 1994; Garrett, 1980; Levelt, 1989). In this way, a thematic role is only initially mapped to a broader syntactic role within the sentence and not to a constituent phrasal structure (e.g., plural or coordinate noun phrase); instead, the planning of the internal phrasal structure occurs at a later stage of the sentence generation process (albeit before articulation). Thus, although we only investigated priming from coordinate to plural noun phrase structures in transitive verb sentences, we would expect to see similar choice priming effects from plural to coordinate noun phrases as both involve the same conceptual features (i.e., always two nouns in the critical noun phrase) and the same thematic mapping processes. The only difference we may observe is speakers becoming slightly more error-prone when producing transitive targets that contain coordinate noun phrases as the use of nouns of two different entities (instead of two of the same entity) may elicit more effortful processing. However, we consider that this possible increase in errors would likely arise during the sentence planning and production stage, and not during the actual syntax selection stage (which occurs before any lexical retrieval or incremental planning; Segaert et al., 2016).

The second aim of our study was to investigate the effect of healthy ageing on syntactic choices. We found convincing evidence of structural priming in young and older adults: both age groups produced more passive targets following passive primes (in line with Hardy et al., 2017; but cf. Heyselaar et al., 2017). Moreover, the magnitude of structural priming in both age groups was equally unaffected by changes to the constituent phrasal structure of the prime. Taken together, this suggests that the abstractness of syntactic representations does not change substantially with age (i.e., older adults continue to represent syntactic structures in a highly abstract form that is undetailed for internal properties), and that there is an age-related preservation of the processes that support syntax selection in 
primed situations. Our finding of an invariant effect of age somewhat contrasts with one of our initial predictions that we expected to observe less structural priming in older adults due to age-related declines in processing speed and transmission strength (MacKay \& Burke, 1990; Salthouse, 1996); however, two alternative plausible explanations remain. Firstly, if syntactic choices are predominately driven by implicit learning mechanisms, as suggested by Chang et al. (2006), then a preservation of implicit learning throughout the lifespan (Fleischman et al., 2004; Light \& Singh, 1987) will elicit a corresponding preservation of structural priming despite age-related declines in other cognitive functions. Secondly, the general slowing associated with ageing may not affect all cognitive networks equally (Fisher, Duffy, \& Katsikopoulos, 2000; Fisk, Fisher, \& Rogers, 1992). In this way, despite slowing and transmission deficits in other areas of language processing, such as within the network that supports the retrieval of phonological components of a word (Burke \& Shafto, 2004), the spreading activation networks that support structural priming (as in Pickering \& Branigan, 1998, and Segaert et al., 2016) may not be so negatively affected by healthy ageing. Indeed, preserved priming effects have been observed in other areas of language processing, such as morphological priming of regularly-inflected words and transparent compounds (Clahsen \& Reifegerste, 2017; Duñabeitia, Marín, Avilés, Perea, \& Carreiras, 2009; Reifegerste, Elin, \& Clahsen, 2018).

Nevertheless, it is important to consider that we found evidence of preserved structural priming effects in older adults in a task in which the demands may not have been great enough to elicit a measurable behavioural difference between age groups. Our task was more difficult than previous ageing priming studies that have included one agent and one patient (Hardy et al., 2017; Heyselaar et al., 2017, 2018; Sung, 2015), since all of our primes and targets consisted of three entities. Nonetheless, active and passive sentences are generally not considered to be the most complex syntactic structures to produce (i.e., they do not contain an embedded clause or a large syntactic operation of movement). Indeed, similar patterns of brain activation have been found in young and older adults when processing passive sentences (Mack, Meltzer-Asscher, Barbieri, \& Thompson, 2013), in contrast to the age differences in brain activity during the comprehension of more complex syntactic structures (Peelle et al., 2010; Tyler et al., 2010). As such, within our active and passive production task, the balance between an individual's neurocognitive capacity and the task 
demands may still have been balanced in favour of 'good' behavioural performance in older adults (i.e., similar structural priming effects to young adults), despite likely declines in overall cognitive capacity (Peelle, 2019). Future work is therefore needed to fully understand the nature of older adults' syntax selection and planning mechanisms in a structural priming task in which the target sentence is syntactically more complex; for example, when the transitive verb sentence is contained within an embedded clause (e.g., "The teacher saw that [the boy is being chased by the girl]") or includes a subordinate clause (e.g., "The boy is being chased by the girl [who has a bow in her hair]") (similar to Branigan et al., 2006, and Fox Tree \& Meijer, 1999). The inclusion of individual difference measures, such as processing speed and verbal knowledge, may also help tease apart the predictions about syntactic priming made by the different models of healthy ageing.

Finally, to consider our onset latency findings, we found that actives were produced significantly quicker than passives in both experiments: this is to be expected as passives are comparatively less frequent in English and therefore take longer to plan and produce (Segaert et al., 2011, 2016). However, we only found a marginal trend toward facilitated effects of target latencies when the prime syntax was repeated, and critically we did not find this effect to vary significantly based on target syntax (active vs. passive) or prime phrase type (whether the prime noun phrase structure matches or mismatches that of the target). ${ }^{5}$ Our findings therefore do not confirm our prediction that latency priming effects would be greater for actives than passives (as according to the two-stage competition model, timing at the selection stage should only be reduced for the more frequent active syntax; Segaert et al., 2016). Likewise, our prediction that the latency priming effect would be greater when the initial noun phrase structure was repeated between the prime and target was not found: in line with an incremental scope of advanced planning, we expected speakers to prioritise the planning of the initial phrase prior to articulation, leading to greater speed benefits when it was repeated (Segaert et al., 2016; Wheeldon, 2013). Moreover, we did not find any age group differences in the magnitude of the latency priming effect as we may have expected if

\footnotetext{
${ }^{5}$ Importantly, we replicated these null effects across two experiments with similar overall onset latencies (Experiment 1, $M=1653 \mathrm{~ms}, S D=576 \mathrm{~ms}$; Experiment 2, $M=1650 \mathrm{~ms}, S D=569 \mathrm{~ms}$; Coefficient $=19.80, \mathrm{SE}=64.57, t=0.31, p=.759$ ).
} 
age-related differences exist in on-line sentence planning (i.e., older adults' increased sensitivity to phrasal properties and boundaries; Hardy et al., 2018).

While our minimal effects of onset latency priming may appear difficult to reconcile with the incremental framework of the two-stage competition model (Segaert et al., 2016), we consider that a more likely explanation for our lack of latency effects lies in the complexity of our stimuli. We used 34 different human and animal characters in the experimental pictures (this was necessary in order to be able to manipulate the noun phrase structure) and there was no predictability between the nouns featured within a prime and target pair. In contrast, in Segaert et al.'s $(2011,2014,2016)$ production priming paradigm, all picture stimuli consisted of either a man and a woman or a boy and a girl; this produced predictability in the characters on the target trials (if the prime featured a man and a woman, the target featured a girl and a boy, and vice-versa). The complexity of the lexical retrieval processes required for our stimuli may therefore have masked effects due to the selection and planning of the target syntactic structure. As such, compared to syntactic choice measures, latency measures of structural priming may be less reliable because they incorporate the time required for lexical retrieval, as well as syntax generation. Further work exploring how latency priming is affected by linguistic factors, in particular the complexity of lexical information, can better inform theories of language production.

In summary, our study is the first to specifically examine the role of constituent phrasal structure, relating to the object and subject noun phrase in a transitive verb sentence, on the magnitude of structural priming. We found robust evidence of structural priming on syntactic choices, which critically did not vary depending on the constituent phrasal structure of the prime. Our findings therefore support models of structural priming that propose syntactic structures are represented in a highly abstract form that is undetailed for internal phrasal structure (Chang et al., 2006; Pickering \& Branigan, 1998). Moreover, we observed choice structural priming effects in equal magnitude in both phrase conditions in young and older adults, suggesting that the abstractness of syntactic representations and the mechanisms that support syntax selection are unaffected by healthy ageing. 


\section{References}

Abrams, L., \& Farrell, M. T. (2011). Language processing in normal aging. In J. Guendouzi, F. Loncke, \& M. . J. Williams (Eds.), The handbook of psycholinguistic and cognitive processes: Perspectives in communication disorders (pp. 49-74). New York: Psychology Press. https://doi.org/10.4324/9780203848005.ch3

Altmann, L. J. P., \& Kemper, S. (2006). Effects of age, animacy and activation order on sentence production. Language and Cognitive Processes, 21(1-3), 322-354. https://doi.org/10.1080/0169096054400006

Baayen, H., Davidson, D. J., \& Bates, D. (2008). Mixed-effects modeling with crossed random effects for subjects and items. Journal of Memory and Language, 59(4), 390 412. https://doi.org/10.1016/j.jml.2007.12.005

Baltes, P. B., \& Baltes, M. M. (1990). Psychological perspectives on successful aging: The model of selective optimization with compensation. In P. B. Baltes \& M. M. Baltes (Eds.), Successful aging: Perspectives from the behavioral sciences (pp. 1-34). New York: Cambridge University Press. https://doi.org/10.1017/cbo9780511665684.003

Barr, D. J., Levy, R., Scheepers, C., \& Tily, H. J. (2013). Random effects structure for confirmatory hypothesis testing: Keep it maximal. Journal of Memory and Language, 68(3), 255-278. https://doi.org/10.1016/j.jml.2012.11.001

Bates, D., Mächler, M., Bolker, B. M., \& Walker, S. C. (2014). Fitting linear mixed-effects models using lme4. Journal of Statistical Software, 67(1), 1-48. https://doi.org/10.18637/jss.v067.i01

Benjamin, B. J. (1981). Frequency variability in the aged voice. Journals of Gerontology, 36(6), 722-726. https://doi.org/10.1093/geronj/36.6.722

Bernolet, S., Hartsuiker, R. J., \& Pickering, M. J. (2007). Shared syntactic representations in bilinguals: Evidence for the role of word-order repetition. Journal of Experimental Psychology: Learning Memory and Cognition, 33(5), 931-949. https://doi.org/10.1037/0278-7393.33.5.931

Bock, K. (1986). Syntactic persistence in language production. Cognitive Psychology, 18(3), 355-387. https://doi.org/10.1016/0010-0285(86)90004-6

Bock, K. (1989). Closed-class immanence in sentence production. Cognition, 31(2), $163-$ 186. https://doi.org/10.1016/0010-0277(89)90022-X

Bock, K., \& Levelt, W. J. M. (1994). Language production: Grammatical encoding. In M. A. Gernsbacher (Ed.), Handbook of psycholinguistics (pp. 945-984). San Diego, CA: Academic Press.

Branigan, H. P. (2007). Syntactic priming. Language and Linguistics Compass, 1(1-2), 1-16. https://doi.org/10.1111/j.1749-818X.2006.00001.x

Branigan, H. P., McLean, J. F., \& Jones, M. (2005). A blue cat or a cat that is blue? Evidence for abstract syntax in young children's noun phrases. In A. Brugos, M. Clark-Cotton, \& $\mathrm{S}$. Ha (Eds.), The proceedings of the 29th Boston University Conference on Language Development (BUCLD). (pp. 109-121). Somerville MA: Cascadilla Press.

Branigan, H. P., \& Pickering, M. J. (2017). An experimental approach to linguistic representation. Behavioral and Brain Sciences, 40, e282. https://doi.org/10.1017/S0140525X16002028

Branigan, H. P., Pickering, M. J., McLean, J. F., \& Stewart, A. J. (2006). The role of local and global syntactic structure in language production: Evidence from syntactic priming. Language and Cognitive Processes, 21(7-8), 974-1010. https://doi.org/10.1080/016909600824609

Burke, D. M., \& Shafto, M. A. (2004). Aging and language production. Current Directions in Psychological Science, 13(1), 21-24. https://doi.org/10.1111/j.0963- 


\subsubsection{6.x}

Burke, D. M., \& Shafto, M. A. (2008). Language and aging. In F. I. M. Craik \& T. A. Salthouse (Eds.), The handbook of aging and cognition (pp. 373-443). New York: Psychology Press. https://doi.org/10.1080/03610738508259280

Chang, F. (2002). Symbolically speaking: A connectionist model of sentence production. Cognitive Science, 26(5), 609-651. https://doi.org/10.1016/S0364-0213(02)00079-4

Chang, F., Dell, G. S., \& Bock, K. (2006). Becoming syntactic. Psychological Review, 113(2), 234-272. https://doi.org/10.1037/0033-295X.113.2.234

Chang, F., Dell, G. S., Bock, K., \& Griffin, Z. M. (2000). Structural priming as implicit learning: A comparison of models of sentence production. Journal of Psycholinguistic Research, 29(2), 217-229. https://doi.org/10.1023/A:1005101313330

Chang, F., Janciauskas, M., \& Fitz, H. (2012). Language adaptation and learning: Getting explicit about implicit learning. Linguistics and Language Compass, 6(5), 259-278. https://doi.org/10.1002/lnc3.337

Cho-Reyes, S., Mack, J. E., \& Thompson, C. K. (2016). Grammatical encoding and learning in agrammatic aphasia: Evidence from structural priming. Journal of Memory and Language, 91, 202-218. https://doi.org/10.1016/j.jml.2016.02.004

Christianson, K., \& Ferreira, F. (2005). Conceptual accessibility and sentence production in a free word order language (Odawa). Cognition, 98(2), 105-135. https://doi.org/10.1016/j.cognition.2004.10.006

Clahsen, H., \& Reifegerste, J. (2017). Morphological processing in old-age bilinguals. In M. Libben, M. Goral, \& G. Libben (Eds.), Bilingualism: A framework for understanding the mental lexicon (pp. 217-248). Amsterdam: John Benjamins Publishing Company.

Cleland, A. A., \& Pickering, M. J. (2003). The use of lexical and syntactic information in language production: Evidence from the priming of noun-phrase structure. Journal of Memory and Language, 49(2), 214-230. https://doi.org/10.1016/S0749-596X(03)000603

Corley, M., \& Scheepers, C. (2002). Syntactic priming in English sentence production: Categorical and latency evidence from an internet-based study. Psychonomic Bulletin \& Review, 9(1), 126-131. https://doi.org/10.3758/BF03196267

Davidson, D. J., Zacks, R. T., \& Ferreira, F. (2003). Age preservation of the syntactic processor in production. Journal of Psycholinguistic Research, 32(5), 541-566. https://doi.org/10.1023/A:1025402517111

de Rosario-Martinez, H. (2015). phia: Post-hoc interaction analysis. $R$ package version 0.21. Retrieved from https://cran.r-project.org/package=phia

Duñabeitia, J. A., Marín, A., Avilés, A., Perea, M., \& Carreiras, M. (2009). Constituent priming effects: Evidence for preserved morphological processing in healthy old readers. European Journal of Cognitive Psychology, 21(2-3), 283-302. https://doi.org/10.1080/09541440802281142

Eckert, M. A. (2011). Slowing down: Age-related neurobiological predictors of processing speed. Frontiers in Neuroscience, 5, 25. https://doi.org/10.3389/fnins.2011.00025

Ferreira, F., Bailey, K. G. D., \& Ferraro, V. (2002). Good-enough representations in language comprehension. Current Directions in Psychological Science, 11(1), 11-15. https://doi.org/https://www.jstor.org/stable/20182754

Ferreira, F., \& Patson, N. D. (2007). The "good enough" approach to language comprehension. Language and Linguistic Compass, 1, 71-83. https://doi.org/10.1111/j.1749-818x.2007.00007.x

Ferreira, V. S. (2003). The persistence of optional complementizer production: Why saying "that" is not saying "that" at all. Journal of Memory and Language, 48(2), 379-398. https://doi.org/10.1016/S0749-596X(02)00523-5 
Ferreira, V. S., \& Bock, K. (2006). The functions of structural priming. Language and Cognitive Processes, 21(7-8), 1011-1029. https://doi.org/10.1080/01690960600824609

Ferreira, V. S., Bock, K., Wilson, M. P., \& Cohen, N. J. (2008). Memory for syntax despite memory amnesia. Psychological Science, 19(9), 940-946. https://doi.org/10.1111/j.1467-9280.2008.02180.x.Memory

Feyereisen, P. (1997). A meta-analytic procedure shows an age-related decline in picture naming: Comments on Goulet, Ska, and Kahn (1994). Journal of Speech, Language, and Hearing Research, 40(6), 1328-1333. https://doi.org/10.1044/jslhr.4006.1328

Fisher, D. L., Duffy, S. A., \& Katsikopoulos, K. V. (2000). Cognitive slowing amoung older adults: What kind and how much? In T. J. Perfect \& E. A. Maylor (Eds.), Models of cognitive aging (pp. 87-124). Oxford, UK: Oxford University Press.

Fisk, A. D., Fisher, D. L., \& Rogers, W. A. (1992). General slowing alone cannot explain age-related search effects: Reply to Cerella (1991). Journal of Experimental Psychology: General, 121(1), 73-78. https://doi.org/10.1037/0096-3445.121.1.73

Fleischman, D. A., Wilson, R. S., Gabrieli, J. D. E., Bienias, J. L., \& Bennett, D. A. (2004). A longitudinal study of implicit and explicit memory in old persons. Psychology and Aging, 19(4), 617-625. https://doi.org/10.1037/0882-7974.19.4.617

Fox, J., \& Weisberg, S. (2011). An R companion to applied regression. Thousand Oaks, CA: Sage.

Fox Tree, J. E., \& Meijer, P. J. A. (1999). Building syntactic structure in speaking. Journal of Psycholinguistic Research, 28(1), 71-92. https://doi.org/10.1023/A:1023239604158

Francis, E. J., Matthews, S., Wong, R. W. Y., \& Kwan, S. W. M. (2011). Effects of weight and syntactic priming on the production of Cantonese verb-doubling. Journal of Psycholinguistic Research, 40(1), 1-28. https://doi.org/10.1007/s10936-010-9152-0

Garrett, M. F. (1980). Levels of processing in sentence production. In B. Butterworth (Ed.), Language production (pp. 117-220). London: Academic Press.

Good, C. D., Johnsrude, I. S., Ashburner, J., Henson, R. N. A., Friston, K. J., \& Frackowiak, R. S. J. (2001). A voxel-based morphometric study of ageing in 465 normal adult human brains. NeuroImage, 14, 21-36. https://doi.org/10.1006/nimg.2001.0786

Hardy, S. M., Messenger, K., \& Maylor, E. A. (2017). Aging and syntactic representations: Evidence of preserved syntactic priming and lexical boost. Psychology and Aging, 32(6), 588-596. https://doi.org/10.1037/pag0000180

Hardy, S. M., Segaert, K., \& Wheeldon, L. (2018). Healthy ageing and sentence production: Disrupted lexical access in the context of intact syntactic planning. BioRxiv, 327304. https://doi.org/10.1101/327304

Hartsuiker, R. J., \& Kolk, H. H. J. (1998). Syntactic facilitation in agrammatic sentence production. Brain and Language, 62(2), 221-254. https://doi.org/10.1006/brln.1997.1905

Heyselaar, E., Segaert, K., Walvoort, S. J. W., Kessels, R. P. C., \& Hagoort, P. (2017). The role of procedural memory in the skill for language: Evidence from syntactic priming in patients with amnesia. Neuropsychologia, 101, 97-105. https://doi.org/https://doi.org/10.1016/j.neuropsychologia.2017.04.033

Heyselaar, E., Wheeldon, L., \& Segaert, K. (2018). Structural priming is supported by different components of non-declarative memory: Evidence from priming across the lifespan. BioRxiv, 190355. https://doi.org/10.1101/190355

Hooper, C. R., \& Cralidis, A. (2009). Normal changes in the speech of older adults: You've still got what it takes, it just takes a little longer! Perspectives on Gerontology, 14(2), 47-56. https://doi.org/10.1044/gero14.2.47

Hwang, H., \& Kaiser, E. (2014). Having a syntactic choice is not always better: The effects of syntactic flexibility on Korean production. Language, Cognition and Neuroscience, 
29(9), 1115-1131. https://doi.org/10.1080/23273798.2013.875212

Hwang, H., \& Kaiser, E. (2015). Accessibility effects on production vary cross-linguistically: Evidence from English and Korean. Journal of Memory and Language, 84, 190-204. https://doi.org/10.1016/j.jml.2015.06.004

Jaeger, T. F. (2008). Categorical data analysis: Away from ANOVAs (transformation or not) and towards logit mixed models. Journal of Memory and Language, 59(4), 434-446. https://doi.org/10.1016/j.jml.2007.11.007

Jaeger, T. F., \& Snider, N. E. (2013). Alignment as a consequence of expectation adaptation: Syntactic priming is affected by the prime's prediction error given both prior and recent experience. Cognition, 127(1), 57-83. https://doi.org/10.1016/j.cognition.2012.10.013

Keizer, E. (2007). The English noun phrase: The nature of linguistic categorization. Cambridge: Cambridge University Press. https://doi.org/10.1017/CBO9780511627699

Kempen, G., \& Hoenkamp, E. (1987). An incremental procedural grammar for sentence formulation. Cognitive Science, 11(2), 201-258. https://doi.org/10.1016/S03640213(87)80006-X

Kemper, S. (1987). Life-span changes in syntactic complexity. Journal of Gerontology, 42(3), 323-328. https://doi.org/10.1093/geronj/42.3.323

Kemper, S., Greiner, L. H., Marquis, J. G., Prenovost, K., \& Mitzner, T. L. (2001). Language decline across the life span: Findings from the Nun Study. Psychology and Aging, 16(2), 227-239. https://doi.org/10.1037/0882-7974.16.2.227

Kemper, S., \& Sumner, A. (2001). The structure of verbal abilities in young and older adults. Psychology and Aging, 16(2), 312-322. https://doi.org/http://dx.doi.org/10.1037/08827974.16.2.312

Levelt, W. J. M. (1989). Speaking: From intention to articulation. Cambridge, MA: MIT Press.

Levelt, W. J. M. (1992). Accessing words in speech production: Stages, processes and representations. Cognition, 42(1-3), 1-22. https://doi.org/10.1016/0010-0277(92)90038

Levelt, W. J. M., \& Maassen, B. (1981). Lexical search and order of mention in sentence production. In W. J. M. Levelt \& W. Klein (Eds.), Crossing the boundaries in linguistics (pp. 221-252). Dordrecht, Netherlands: D. Reidel Publishing Company.

Light, L. L., \& Singh, A. (1987). Implicit and explicit memory in young and older adults. Journal of Experimental Psychology: Learning, Memory, and Cognition, 13(4), 531541. https://doi.org/10.1037/0278-7393.13.4.531

Mack, J. E., Meltzer-Asscher, A., Barbieri, E., \& Thompson, C. K. (2013). Neural correlates of processing passive sentences. Brain Sciences, 3(3), 1198-1214. https://doi.org/10.3390/brainsci3031198

MacKay, D. G., \& Abrams, L. (1998). Age-linked declines in retrieving orthographic knowledge: Empirical, practical, and theoretical implications. Psychology and Aging, 13(4), 647-662. https://doi.org/10.1037/h0090331

MacKay, D. G., \& Burke, D. M. (1990). Cognition and aging: A theory of new learning and the use of old connections. In T. M. Hess (Ed.), Aging and cognition: Knowledge organization and utilization (pp. 213-263). New York: Elsevier Science. https://doi.org/10.1016/S0166-4115(08)60159-4

Mahowald, K., James, A., Futrell, R., \& Gibson, E. (2016). A meta-analysis of syntactic priming in language production. Journal of Memory and Language, 91, 5-27. https://doi.org/10.1016/j.jml.2016.03.009

Malhotra, G., Pickering, M. J., Branigan, H. P., \& Bednar, J. A. (2008). On the persistence of structural priming: Mechanisms of decay and influence of word-forms. In B. C. Love, K. McRae, \& V. M. Sloutsky (Eds.), Proceedings of the 30th Annual Conference of the Cognitive Science Society (pp. 657-662). Austin, TX: Cognitive Science Society. 
Martin, R. C., Crowther, J. E., Knight, M., Tamborello, F. P., \& Yang, C. L. (2010). Planning in sentence production: Evidence for the phrase as a default planning scope. Cognition, 116(2), 177-192. https://doi.org/10.1016/j.cognition.2010.04.010

Martin, R. C., Yan, H., \& Schnur, T. T. (2014). Working memory and planning during sentence production. Acta Psychologica, 152, 120-132. https://doi.org/10.1016/j.actpsy.2014.08.006

Melinger, A., \& Cleland, A. A. (2011). The influence of sentential position on noun phrase structure priming. Quarterly Journal of Experimental Psychology (2006), 64(11), 22112235. https://doi.org/10.1080/17470218.2011.586709

Melinger, A., \& Dobel, C. (2005). Lexically-driven syntactic priming. Cognition, 98(1), B11-B20. https://doi.org/10.1016/j.cognition.2005.02.001

Menenti, L., Gierhan, S. M. E., Segaert, K., \& Hagoort, P. (2011). Shared language: Overlap and segregation of the neuronal infrastructure for speaking and listening revealed by functional MRI. Psychological Science, 22(9), 1173-1182. https://doi.org/10.1177/0956797611418347

Messenger, K., Branigan, H. P., \& McLean, J. F. (2011). Evidence for (shared) abstract structure underlying children's short and full passives. Cognition, 121(2), 268-274. https://doi.org/10.1016/j.cognition.2011.07.003

Morris, R. J., \& Brown, W. S. (1994). Age-related differences in speech variability among women. Journal of Communication Disorders, 27(1), 49-64. https://doi.org/10.1016/0021-9924(94)90010-8

Myachykov, A., Scheepers, C., Garrod, S., Thompson, D., \& Fedorova, O. (2013). Syntactic flexibility and competition in sentence production: The case of English and Russian. Quarterly Journal of Experimental Psychology, 66(8), 1601-1619. https://doi.org/10.1080/17470218.2012.754910

Nasreddine, Z. S., Phillips, N. A., Bedirian, V., Charbonneau, S., Whitehead, V., Collin, I., ... Chertkow, H. (2005). The Montreal cognitive assessment, MoCA: A brief screening for mild cognitive impairment. Journal of the American Geriatrics Society, 53, 695-699. https://doi.org/10.1111/j.1532-5415.2005.53221.x

Peelle, J. E. (2019). Language and aging. In G. I. de Zubicaray \& N. O. Schiller (Eds.), The Oxford handbook of neurolinguistics. Oxford, UK: Oxford University Press. https://doi.org/10.1016/B978-0-12-809324-5.01889-7

Peelle, J. E., Troiani, V., Wingfield, A., \& Grossman, M. (2010). Neural processing during older adults' comprehension of spoken sentences: Age differences in resource allocation and connectivity. Cerebral Cortex, 20(4), 773-782. https://doi.org/10.1093/cercor/bhp142

Pickering, M. J., \& Branigan, H. P. (1998). The representation of verbs: Evidence from syntactic priming in language production. Journal of Memory and Language, 39(4), 633-651. https://doi.org/10.1006/jmla.1998.2592

Pickering, M. J., \& Ferreira, V. S. (2008). Structural priming: A critical review. Psychological Bulletin, 134(3), 427-459. https://doi.org/10.1037/0033-2909.134.3.427

R Core Team. (2015). A language and enviroment for statistical computing. Vienna, Austria: R Foundation for Statistical Computing. Retrieved from https://www.r-project.org/

Rabaglia, C. D., \& Salthouse, T. A. (2011). Natural and constrained language production as a function of age and cognitive abilities. Language and Cognitive Processes, 26(10), 1505-1531. https://doi.org/10.1080/01690965.2010.507489

Reifegerste, J., Elin, K., \& Clahsen, H. (2018). Persistent differences between native speakers and late bilinguals: Evidence from inflectional and derivational processing in older speakers. Bilingualism: Language and Cognition, 1-16. https://doi.org/10.1017/S1366728918000615 
Reitter, D., Keller, F., \& Moore, J. D. (2011). A computational cognitive model of syntactic priming. Cognitive Science, 35(4), 587-637. https://doi.org/10.1111/j.15516709.2010.01165.x

Salthouse, T. A. (1996). The processing speed theory of adult age differences in cognition. Psychological Review, 103(3), 403-428. https://doi.org/10.1037/0033-295X.103.3.403

Scheepers, C., Raffray, C. N., \& Myachykov, A. (2017). The lexical boost effect is not diagnostic of lexically-specific syntactic representations. Journal of Memory and Language, 95, 102-115. https://doi.org/10.1016/j.jml.2017.03.001

Schneider, W., Eschman, A., \& Zuccolotto, A. (2002). E-prime user's guide. Pittsburgh, PA: Psychology Software Tools Inc.

Segaert, K., Menenti, L., Weber, K., \& Hagoort, P. (2011). A paradox of syntactic priming: Why response tendencies show priming for passives, and response latencies show priming for actives. PLoS ONE, 6(10), e24209. https://doi.org/10.1371/journal.pone.0024209

Segaert, K., Weber, K., Cladder-Micus, M., \& Hagoort, P. (2014). The influence of verbbound syntactic preferences on the processing of syntactic structures. Journal of Experimental Psychology: Learning, Memory, and Cognition, 40(5), 1448-1460. https://doi.org/10.1037/a0036796

Segaert, K., Wheeldon, L., \& Hagoort, P. (2016). Unifying structural priming effects on syntactic choices and timing of sentence generation. Journal of Memory and Language, 91, 59-80. https://doi.org/10.1016/j.jml.2016.03.011

Shafto, M. A., Burke, D. M., Stamatakis, E. A., Tam, P. P., \& Tyler, L. K. (2007). On the tipof-the-tongue: Neural correlates of increased word-finding failures in normal aging. Journal of Cognitive Neuroscience, 19(12), 2060-2070. https://doi.org/10.1162/jocn.2007.19.12.2060

Smith, M., \& Wheeldon, L. (1999). High level processing scope in spoken sentence production. Cognition, 73(3), 205-246. https://doi.org/10.1016/S0010-0277(99)00053-0

Smith, M., \& Wheeldon, L. (2001). Syntactic priming in spoken sentence production - an online study. Cognition, 78(2), 123-164. https://doi.org/10.1016/S0010-0277(00)001104

Smith, T., Gildeh, N., \& Holmes, C. (2007). The Montreal Cognitive Assessment: Validity and utility in a memory clinic setting. Canadian Journal of Psychiatry, 52(5), 329-332. https://doi.org/10.1177/070674370705200508

Sung, J. E. (2015). Age-related changes in sentence production abilities and their relation to working-memory capacity: Evidence from a verb-final language. PLOS ONE, 10(4). https://doi.org/10.1371/journal.pone.0119424

Temperley, D. (2005). The dependency structure of coordinate phrases: A corpus approach. Journal of Psycholinguistic Research, 34(6), 577-601. https://doi.org/10.1007/s10936005-9165-2

Tyler, L. K., Shafto, M. A., Randall, B., Wright, P., Marslen-Wilson, W. D., \& Stamatakis, E. A. (2010). Preserving syntactic processing across the adult life span: The modulation of the frontotemporal language system in the context of age-related atrophy. Cerebral Cortex, 20(2), 352-364. https://doi.org/10.1093/cercor/bhp105

United Nations. (2011). International standard classification of education. Montreal, Canada: UN Institute for Statistics. Retrieved from http://uis.unesco.org/en/topic/internationalstandard-classification-education-isced

Verhaeghen, P. (2003). Aging and vocabulary scores: A meta-analysis. Psychology and Aging, 18(2), 332-339. https://doi.org/10.1037/0882-7974.18.2.332

Wheeldon, L. (2013). Producing spoken sentences: The scope of incremental planning. In S. Fuchs, M. Weirich, D. Pape, \& P. Perrier (Eds.), Speech production and perception: 
Speech planning and dynamics (pp. 97-118). Frankfurt, Germany: Peter Lang International Academic Publishers.

Wheeldon, L., \& Smith, M. (2003). Phrase structure priming: A short-lived effect. Language and Cognitive Processes, 18(4), 431-442. https://doi.org/10.1080/01690960244000063

Wingfield, A., \& Grossman, M. (2006). Language and the aging brain: Patterns of neural compensation revealed by functional brain imaging. Journal of Neurophysiology, 96(6), 2830-2839. https://doi.org/10.1152/jn.00628.2006

Yan, H., Martin, R. C., \& Slevc, L. R. (2018). Lexical overlap increases syntactic priming in aphasia independently of short-term memory abilities: Evidence against the explicit memory account of the lexical boost. Journal of Neurolinguistics, 48, 76-89. https://doi.org/10.1016/j.jneuroling.2017.12.005

Ziegler, J., Snedeker, J., \& Wittenburg, E. (2017). Priming is swell, but it's far from simple: Comments on Branigan and Pickering (2017). Brain and Behavioral Sciences, 40, e312. 